\title{
Silent and Independent: Student Use of Academic Library Study Space
}

Katharine Hall

Biology and Exercise Sciences Librarian

Concordia University

katharine.hall@concordia.ca

Dubravka Kapa

Associate University Librarian, Research \& Graduate Studies

Concordia University

dubravka.kapa@concordia.ca

\section{Abstract}

In the fall of 2012, Concordia University Libraries started planning for renovations which would result in the increase of study spaces in one of its two libraries and the reduction at the other. In order to maximize the functionality of the reduced study space footprint, a survey and focus groups were used to better understand the specific space needs of the library's campus community. The study revealed differences in the use of the library among the respondents from different programs of study. Respondents enrolled in science programs visit the library more often but seek assistance less than the respondents in social sciences programs. The survey comments and focus groups pointed to students' dissatisfaction with the quality of study spaces the library offers, either for individual or group study. Library users wanted larger table space, comfortable furniture, and more desktop computers. The overall ambience of study spaces proved to be rather important and a large point of dissatisfaction. The findings from the study have provided valuable information on how to prioritize targeted improvements and which aspects of the library's space and services to highlight when promoting library services to different departments.

\section{Keywords}

academic libraries; study spaces; library use; undergraduate students; science students; small campus library

\section{Context and Introduction}

Concordia University, located in Montreal, Quebec, has two campuses, each with its own library. The Vanier Library is located on the Loyola campus which serves approximately $15 \%$ of Concordia's student body. Loyola is home to the departments of Chemistry \& Biochemistry, Biology, Physics, Exercise Sciences, Psychology \& Neuroscience, Applied Human Sciences, Journalism, and Communications. As part of a 
larger renovation plan for the library system, the renovations at the Vanier Library will decrease the available floor space for collections and for study. The higher proportion of science programs at Loyola raised the question of whether the Loyola campus students have specific needs that we should pay attention to.

Routinely collected Vanier Library statistics showed a steady number of library visits and a sustained decrease in both the borrowing activity and the number of questions received at the reference desk in the last 10-15 years. This discrepancy in the number of library visits and use of the library's reference and circulation services encouraged us to consider the role of the library's study spaces and other services such as computers and printing.

In the fall of 2012, an evaluation project was undertaken to determine the study space needs of the Loyola campus student population, as well as the priorities in the renovation plans for the Vanier Library. The data collected would provide input on student use of the library's spaces and inform our decisions when looking for the best way to minimize the impact of the loss of overall floor space dedicated to both individual and group study. An equally important aspect of the project was to provide an opportunity to directly involve the students and library staff in the process of reconfiguring the study spaces so as to develop relationships across campus and to help integrate the library into students' life on campus.

There have been many studies about student use of space in academic libraries often for the purpose of planning for renovations, or to assess the success of recent renovations. Most of the studies collected the data through surveys and focus groups but there are studies that used ethnographic methods as well. A good overview of surveys in academic libraries was given by Creaser. One of the more recent studies, done by Bailin at the University of New South Wales, attempted to assess how well the recently renovated library met the needs of students. Bailin found that near equal proportions of students were coming to the library for the quiet study space, lounge space and to use the computers.

A study conducted by Walton, at the Loughborough University Library, attempted to determine why students chose certain areas of the library to study and what qualities drew them to those study spaces. He discovered that majority of students placed high importance on physical environment and low noise levels when selecting a study location within the library. This study was followed up several years later with an ethnographic study of students' behaviour in the library (Bryant, Matthews and Walton). The spent over 40 hours in unobtrusive observation of one specific open concept study area. They were able to provide evidence of the popularity of that open and flexible learning environment.

Webb, Schaller and Hunley examined space use within the library, wanting to understand students' choices and preferences. Comfort of the study place proved to be a very individual feeling but also an important reason for choosing one place over another. 
Vaska, Chan and Powelson examined the different space needs of users of a health sciences library. They found that the majority of their library users preferred the study carrels (58.3\%) because they were quiet and set apart from the main traffic of the library. There is a strong preference for carrels near windows. When the respondents were asked for suggestions for improvement, the response fell into three main categories: technological requirements, such as power outlets; furnishings and facilities, such as more comfortable chairs and better lighting; and the final category was comfort and general ambience.

Brown-Sica conducted an assessment project of the Auraria Library located in Denver, Colorado, an urban library that serves a very diverse population of commuter students. She employed a Participatory Action Research (PAR) approach which fosters selfevaluation and participatory problem solving. As Brown-Sica describes it, "subjects of the study perform some of the research and/or interpret the data themselves, with the aim of learning from the process to generate evidence to improve an existing problem" (220). The Auraria Library students listed more computers, better furniture, a more attractive environment, and more study spaces as being important improvements the library could make. They also highly stressed the importance of power outlets.

The existing studies provided a general overview as to what university students see as being important but considering the unique demographics of Loyola campus, we decided to test whether there are some differences that we need to pay attention to when planning for renovations.

\section{Methodology}

It was decided that a mixed methods approach consisting of a survey and focus groups was the best approach to gather both quantitative and qualitative information for our project. It was the participatory and collaborative aspect that the authors found to be suitable for this project. We obtained ethics approval from Concordia's Office of Research to run a survey and conduct focus groups.

Inspired by Brown-Sica's PAR approach the authors decided to include library staff and campus students in the evaluation process. We chose to partner with members of the Applied Human Sciences (AHSC) department. AHSC programs focus on the human elements of social systems with an educational philosophy centered on experiencebased learning. AHSC students are trained to help with organizational change, act as mediators, and facilitate community and organization development. The programs have a substantial component of field work within their course requirements and their faculty have expertise in conducting surveys and focus groups.

Given the unique nature of the AHSC program, it was felt that their students and faculty would be good partners for this project. The authors approached a faculty member in the department who is an expert in research methodologies to ask for her support with the project. She provided some initial advice on research methodology and reviewed the survey so as to ensure that it was well constructed and that it would provide the data 
we needed. The faculty member volunteered to pretest it with her undergraduate Research Methodology class. She also put the authors in contact with another faculty member who was looking for fieldwork opportunities for his graduate students. As a result, the authors partnered with three graduate students who helped with the focus group design, implementation and analysis as part of their program's fieldwork requirements.

This partnership was very rewarding and useful as it provided the perspective of those not connected to the library world. The AHSC graduate students were very knowledgeable on qualitative research methods and were excellent mediators in focus groups. The only major difficulty with collaborating with students was the timing constraints it added to the project. For example, focus groups could not take place during the same semester as the survey and had to be timed to correspond with the course assignment timeline of our partners. This also meant we were unable to add more focus groups when the first sessions were poorly attended. However, the whole process was a good learning experience for us and our AHSC partners helped us see the library from our students' perspective.

\section{Survey}

Inspired by the methods of Brown-Sica, potential survey questions were developed with the participation of all librarians working at the Vanier Library. The questions were then ranked and reworded to focus on space issues. The survey was designed and hosted on SurveyMonkey and the finalized version of the questions can be seen in Appendix 1.

The final list included questions on library use patterns, improvements needed, satisfaction with current library spaces, importance of different features of study spaces, and the need for group study spaces. Some basic demographic data were also collected. There were 28 questions in total, with 16 that allowed for written comments if the user so desired.

In the survey preamble, students were informed it would take ten minutes to answer the survey, however the completion time would vary greatly depending on the respondent and how much time they took with the written comments. Additionally, SurveyMonkey allowed for respondents to be seamlessly guided to the next relevant question by skipping questions that were not relevant based on their previous answers. For example, if a respondent said that they never did group work then the four questions about group study spaces were omitted from their survey. Using this function also allowed us to prevent respondents who were not students from answering the survey.

In November 2012, the survey link was distributed via email to a random sample of students registered in any course taught on the Loyola campus. No print version of the survey was distributed. The initial invitation email was followed by an email reminder two weeks later. 
There are approximately 6,000 students registered in programs based at the Loyola campus, where the Vanier Library is located. The email list received from the IT department consisted of students registered in any course given at Loyola campus whether or not their program of study was at the Loyola campus. Approximately 44\% of emails on the list were for students registered in programs based on the other campus. This may have influenced the rate of response as these students most likely used the downtown campus library where they had most of their classes and had very little interest in the Loyola campus library.

After the survey was closed, it was discovered that the email list contained duplicate entries, meaning that the sample size was smaller than intended. After eliminating duplicates from the count, it was calculated that the survey was sent to 3,478 unique emails. There were 275 responses: 222 complete responses, 45 partial responses and eight disqualified responses. Only the 267 complete and partially complete responses were analyzed (approximately $80 \%$ of which were respondents registered in a Loyolabased program) which is a response rate of $7.7 \%$. Considering that $44 \%$ of invitations were sent to students not registered in Loyola-based programs, this relatively low response rate is understandable.

Additionally, due to the limited budget for this project, no incentive to complete the survey was offered. The lack of incentive may have further reduced the number of respondents, however the optimistic interpretation is that it increased the number of responses from individuals who legitimately care about the study space at the Vanier Library. For comparison, Concordia's LibQual 2013 survey, where incentives such as tuition credits were offered, had a response rate of $9.5 \%$ (Association of Reserach Libraries).

Initial analysis of the survey was completed using SurveyMonkey's analysis tools. Additional analysis of the quantitative data and the coding of the qualitative comments was done by the authors in Microsoft Excel. The majority of the questions that allowed for a written response were questions in which respondents were presented with multiple options and a comment box. The comment boxes offered a way for the respondents to clarify their choices or specify another option. These comments were examined and assigned categories such as, computers, printers, study space, group study space, individual study space, food, ambience, power outlets, books/articles, and services.

\section{Focus Groups}

After the initial analysis of the survey results, the authors started working with the three AHSC graduate students to organize, run, and analyze three student focus groups. Frequently, the comments in the survey would point to problem areas without providing much explanation. For example, several respondents commented that the library needed more comfortable chairs. These comments did not elaborate on what was uncomfortable about the current chairs or which chairs they were discussing, which was a challenge, as the library has several different models of chairs. The issues that 
emerged from the survey were used to create a schedule of open-ended questions to guide the focus group discussions (Appendix 2).

To recruit students for the focus groups, flyers were placed around the library and emails were sent to students who had participated in the survey and expressed interest in participating in focus groups. Announcements were made over the library's PA system 15 minutes prior to the start of the sessions, while our research assistant approached students sitting in the library and asked if they would like to join the focus group. Three focus groups were planned, but only two were held due to a lack of participants. A total of 12 students participated in the focus groups. Due to the time constraints of the research partners in AHSC, the focus groups were planned for the end of March and the beginning of April, 2013. This timing was unfortunate, as it was leading into the students' exam period.

For each of the focus groups one of the AHSC graduate students acted as moderator, with a librarian as co-moderator. Several staff members and librarians volunteered to serve as note-takers and observe the non-verbal cues of the participants. There was some discussion about whether having library staff present at the focus groups would influence the results. We felt it would be beneficial to have staff participate so they could hear the comments regarding study spaces. Our research partners in AHSC advised that since no questions would be asked about the services provided by library staff, the benefits of having staff learn the process and hear the students' feedback outweighed the possibility of students holding back any negative comments. Judging from the interactions with the limited number of students who did participate, it did not appear as the participants held back any responses due to the presence of staff. Staff attendance at focus groups allowed for them to hear, first-hand, feedback from students on the topic library space. Such feedback is seldom brought by students to the service desk, and as such hearing the comments directly in the focus groups made space issues feel more real to staff.

After the first focus group session, library staff met with the AHSC graduate students to analyze the notes from the session and code it for themes. As part of their fieldwork requirements, the AHSC students coded the remainder of the sessions and presented the authors with a report of the reoccurring themes with specific examples from the session notes.

\section{Observations}

Although an ethnographic methodology was often employed in the literature and would have been a nice complement to the survey and focus groups, this method was not possible due to a lack of time to obtain additional ethics approval and then gather and analyze that type of data. However, the authors' research assistant took notes about student behaviour in several different locations of the library, during different times of the day, to capture the behaviours of a variety of students. She was asked to capture in her notes absolutely everything that the students did in that space. 
Our research assistant was a MLIS student who blended in well with other students in the study spaces. Her notes were used to check against the comments from the survey and focus groups to make sure there were no large omissions. She observed students using laptops, reading textbooks, single students occupying study tables and spreading out their materials, students studying in pairs and having whispered conversations, as well as students eating in the library. This data was not used in the final analysis, as their initial examination did not indicate any issues that were not already explored in the survey or focus groups.

\section{Results \& Discussion}

The results of the survey and focus groups are discussed thematically and presented together when applicable to that theme. Not every survey question had a corresponding focus group question as the focus group questions concentrated on eliciting qualitative data and clarifying issues raised by the survey.

\section{Campus Students}

There are indications in the literature that students on different campuses of the same university might have different needs. In her analysis of results from a number of surveys done in UK academic libraries, Creaser concludes that "in multi-campus institutions, it is highly desirable to analyze responses by campus, particularly where there are significant subject specialisms" (5). The Loyola campus, as mentioned earlier, is home to all science departments and just a few of many social sciences departments at Concordia.

The survey included questions about respondents' demographics. This was used to understand how respondents' demographics compare with campus students'

demographics. Answers to these questions also allowed the researchers to analyze potential differences in use of the library by different facets such as program of study, age, or proximity to campus.

All survey respondents were registered, at minimum, in one course taught at the Loyola campus. However, $80 \%$ of respondents had the majority of their classes on the Loyola campus. Of these respondents, $62 \%$ were between $18-22$ years old compared to $40 \%$ of the overall Concordia student population. The Loyola-based respondents were predominantly undergraduate students (92\%) with a full-time course load $(79.8 \%)$ while, according to Concordia's Office of Institutional Planning, 83\% of all Concordia students are undergraduate students and $66.5 \%$ have a full-time course load. There was also a high percentage of commuter students (77.5\%) among Loyola respondents.

The study habits and subsequent space and equipment needs of students may vary among disciplines. Students in certain disciplines may use the space more, or differently, than others. Figure 1 shows the percentage distribution of programs among survey respondents registered in programs based on the Loyola campus, and the actual percentage distribution of all students in those programs. The science students were 
over-represented in the survey: $48 \%$ of respondents with a program of study based at the Loyola campus were in science departments while, according to the University's statistics, only 34\% of Loyola campus students are registered in these departments (Figure 2). It is possible that since the survey preamble highlighted that the focus was on study space, those students who use the library study spaces were more motivated to participate in the survey, and science students happened to be proportionally more represented in this group.

The intention was to use the results of the survey to inform the limited renovations of study spaces and we were satisfied to hear from only those students who are actually using the library. If there were to be a large scale renovation project, hearing the study space needs of both the students who are currently using the library and those who are not would be important. Understanding the reasons students choose not to use the library, would be helpful in determining whether these students are merely dissatisfied with the current offerings of the library and could be persuaded to use the library if certain improvements were made. It is also likely that there is a group of students who are satisfied with the space provided elsewhere and who would not be persuaded to use the library regardless of changes made.

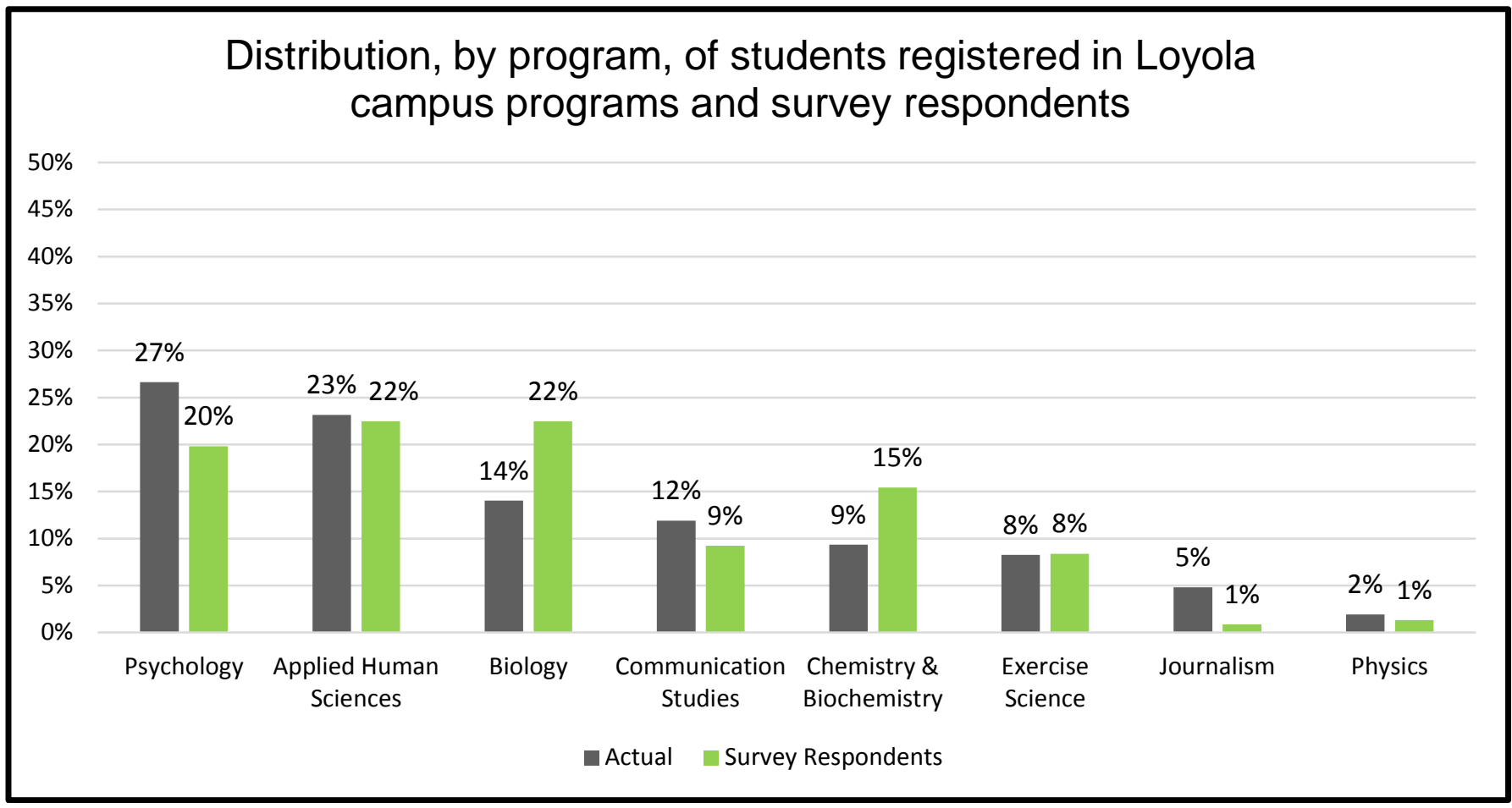

Figure 1. Distribution, by program, of students registered in Loyola campus programs and the distribution of respondents' program of study. Respondents whose program of study is not at the Loyola campus were not included. 


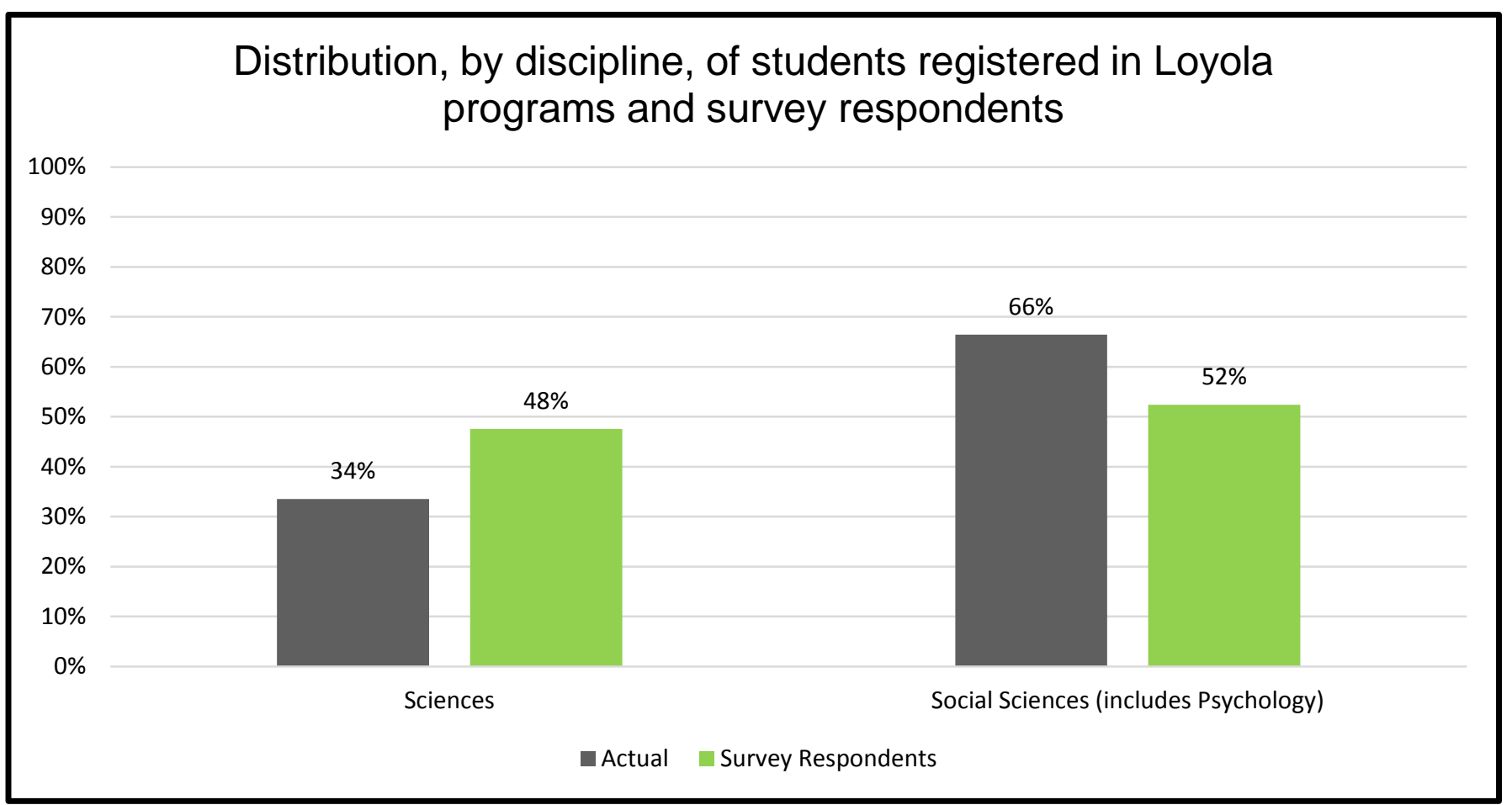

Figure 2. Distribution, by discipline, of students registered in Loyola campus programs and the respondents registered in these programs. Respondents whose program of study is not at the Loyola campus were not included.

\section{Frequency of Library Use}

As detailed in Figure 3, 59\% of respondents use the library at least once per week. This is consistent with the Association of Reseearch Libraries' (ARL) LibQual 2013 report for Concordia University which found that $59 \%$ of respondents use the library weekly (39). This would mean that the Vanier Library survey respondents are no different from other Concordia students in terms of frequency of use. 


\section{Frequency of library visits for all respondents}

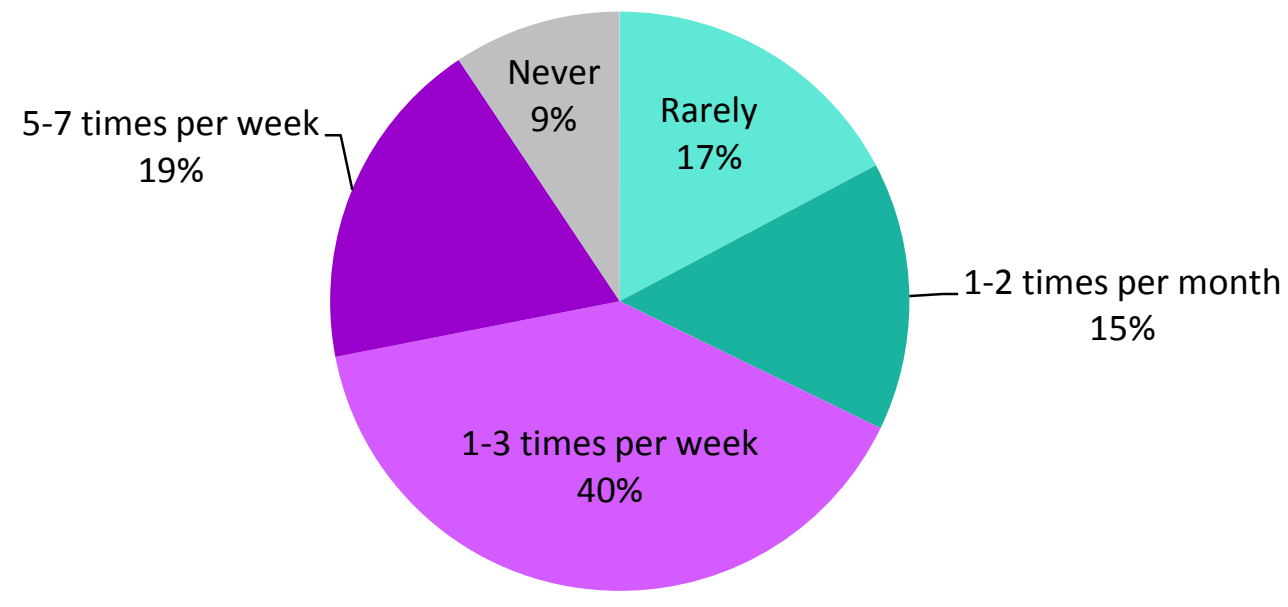

Figure 3. Frequency of all respondents' visits to the Vanier Library.

Respondents' use patterns differ from one another when analyzed by program. Figure 4 shows that $35 \%$ of Biology respondents and $26 \%$ of Chemistry \& Biochemistry respondents use the library on an almost daily basis compared with the respondents registered in social science disciplines, such as AHSC, where only a minority of respondents (10\%) visit daily. This is in agreement with a study examining library use by discipline done by Collins, which found that science students visit the library more often than social science students. 


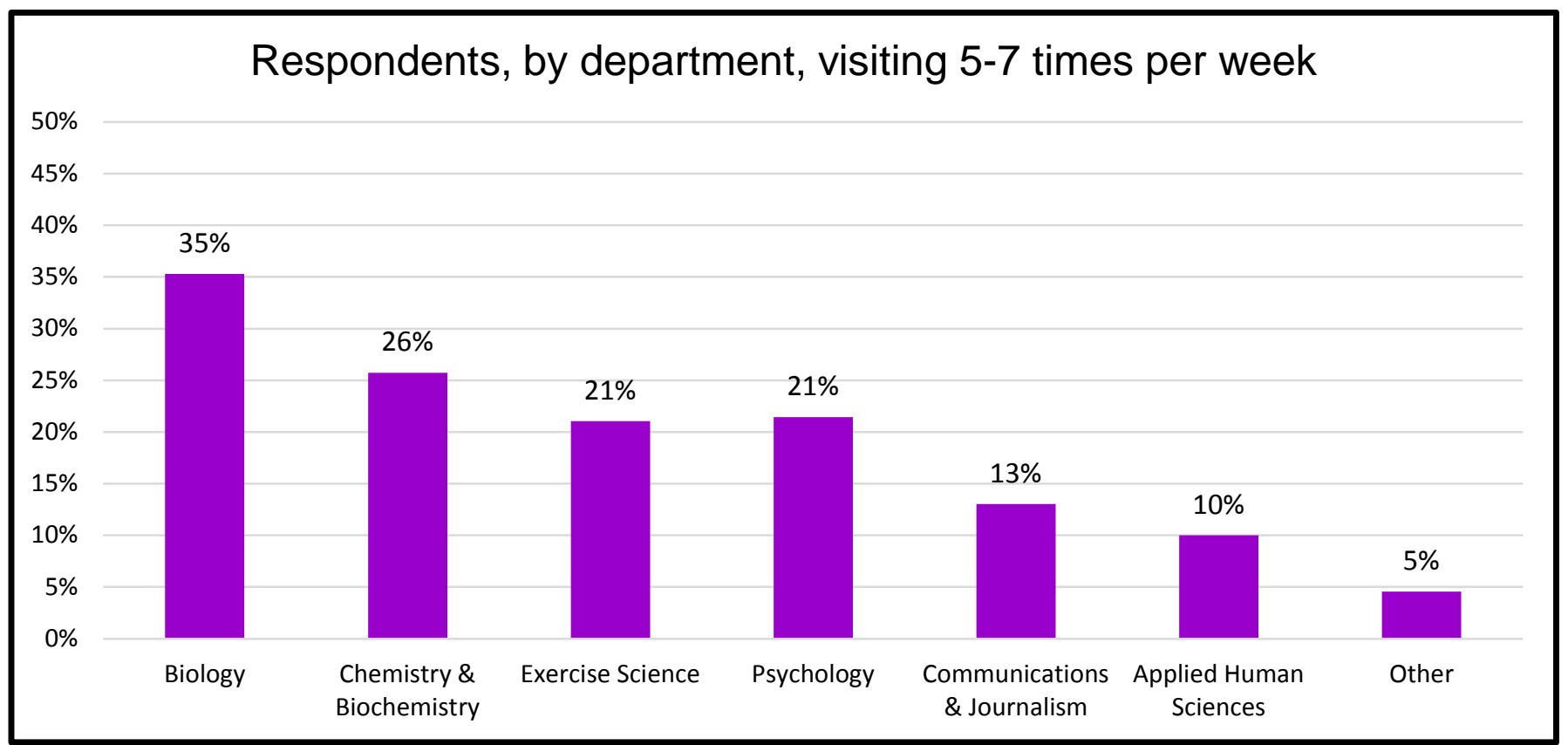

Figure 4. Percentage of respondents within each department who use the Vanier Library 5-7 times per week.

\section{Reasons for Visiting the Vanier Library}

Figure 5 shows that the overwhelming majority of respondents come to the library to use the quiet study space (84\%) or to use equipment such as printers $(57 \%)$ or computers (50\%). Group study rooms are also high on the list (40\%). Some 35\% of respondents stated that they are coming to the library to borrow books. This is less than reported elsewhere. For example, a 2010 OCLC report states that $60 \%$ of college students come to the library to borrow print books and 50\% come to access copies of articles/journals (De Rosa et al. 59). This large difference may be due to the fact that as the survey preamble highlighted the focus was study space, people who borrow items from the library, but do not use the space, opted not to participate in the survey. Also, the proportion of science students among respondents (48\%) is likely higher than in a general population of students in a comprehensive university. This may have contributed to such a low percentage of respondents who come to the library to borrow books, as science students are known to use fewer books in their papers and projects than social science students (Magrill and St. Clair). 


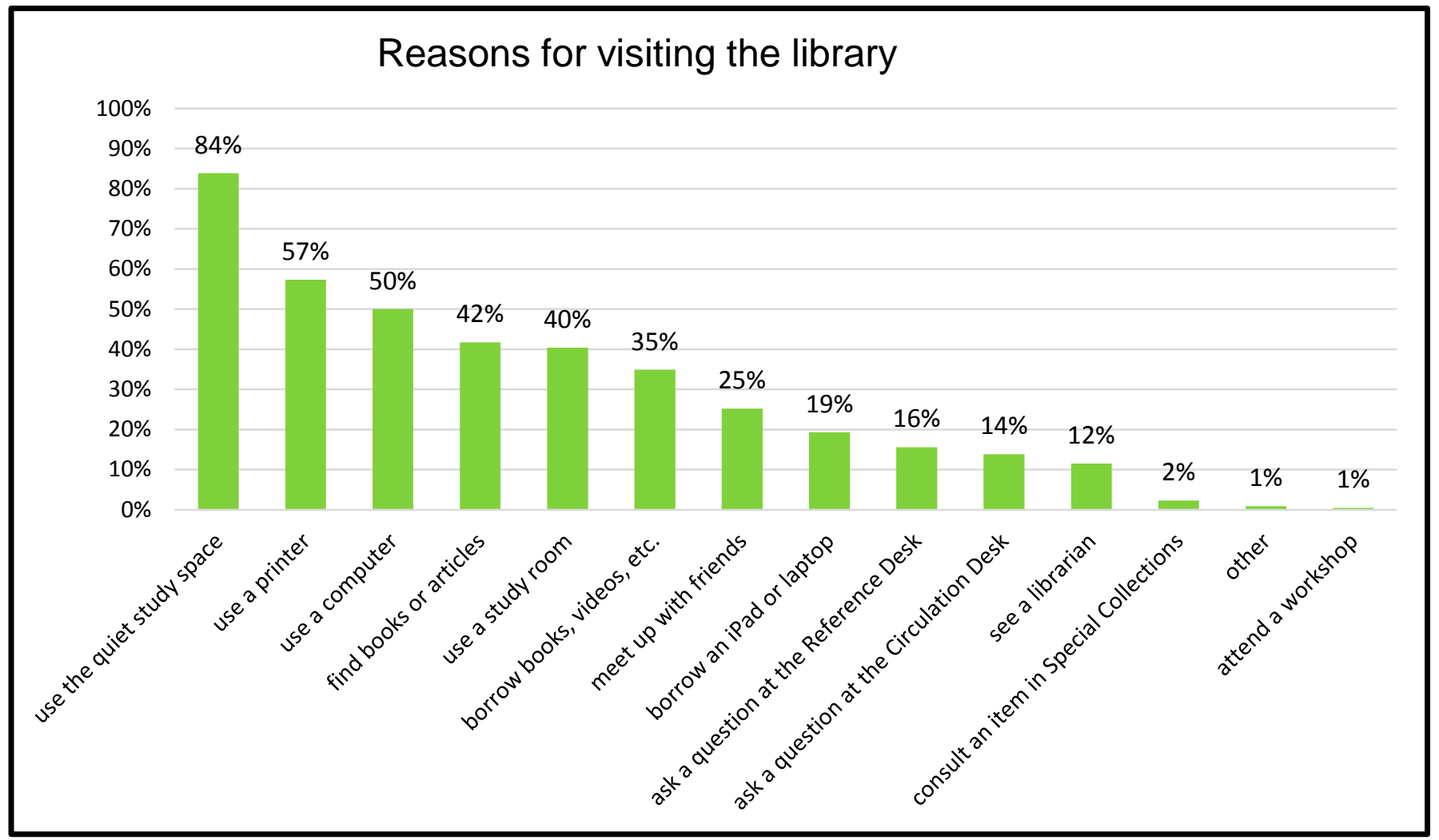

Figure 5. Percentage of respondents who indicated a particular reason for visiting the library. Respondents were allowed to select as many reasons as applied.

Use of the face-to-face services was low: $16 \%$ come to ask a question at the reference desk, $14 \%$ to ask a question at the circulation desk, and $12 \%$ to meet with a librarian. Figure 6 shows that there are some differences among students in different programs in using face-to-face services. For example, 30\% of respondents in AHSC as well as in Chemistry \& Biochemistry indicated that they come to the library to ask a librarian or library staff member a question. On the other side of the spectrum are Biology respondents who almost never utilize these services. Exercise Science, Physics, Psychology, Journalism, and Communication Studies respondents also show similar use patterns to Biology for face-to-face services. This is quite different from the 2010 OCLC document that reports $51 \%$ of college students visited the library to "get assistance with research" (De Rosa et al. 59). Here, also, the differences might be due to the nature of the survey, or to the proportionally higher number of science student respondents, resulting in a lower response rate from students who come to the library for staff assistance. 


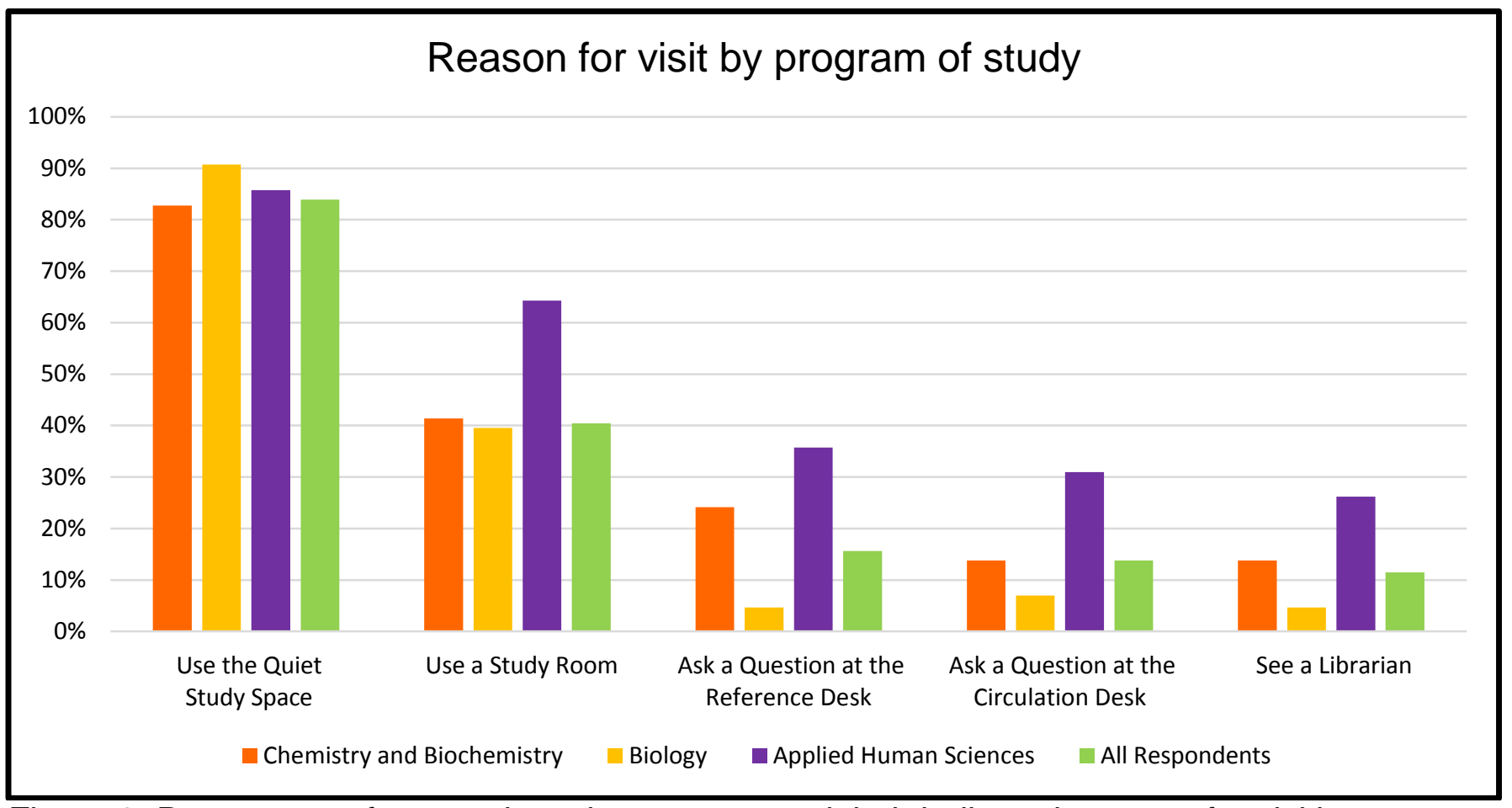

Figure 6. Percentage of respondents by program and their indicated reasons for visiting the library.

\section{Areas Needing Improvement}

Students were asked (Question 13) to give their opinion about improvements they would like to see in the library. Prior to this question they were not asked about their experience with the library or their opinions on specific areas so as not to influence what they would indicate here. It was a deliberate decision not to provide any options or choices to select, but rather allowing students to bring forward anything they thought needed improvement. Their answers were coded into categories (e.g., group study spaces, printers, food, etc.) that corresponded to the reasons for visiting the library. Figure 7 shows the distribution of responses along with respondents' reasons for visiting the library. This provided a way to see if the items respondents viewed as needing improvement were features or services that they frequented the library to use. The number one reason for respondents' visit to the library was to use the quiet study space and study space was the item most frequently mentioned as needing improvement. While only $40 \%$ of respondents visited the library to use group study rooms, they were the second most frequently cited area identified as needing improvement.

Question 13 asked for the one thing respondents would improve about the library, resulting in many, very brief, two-or-three word responses that did not provide much explanation. For example:

The carpet

Study spaces

Appearance 


\section{More sitting space \\ More computers \\ More study rooms}

This lack of detail alerted us to broad areas of dissatisfaction and helped shape the questions for the focus group.

Figure 7 does not show the nature of the comments. For example, 55\% of respondents left comments about the silent study space, but their comments range from the need for more silent study areas to a dislike of the layout and configuration of the space and furniture (e.g., tables versus study carrels):

\section{More quiet study space}

Add more cubicle tables

More single study spaces. Not beside other desks or people.

Although prompted to give a negative comment (i.e., input on improvements needed), $10 \%$ of users left positive comments or considered this question to be not applicable, (e,g., "It is fine the way it is").

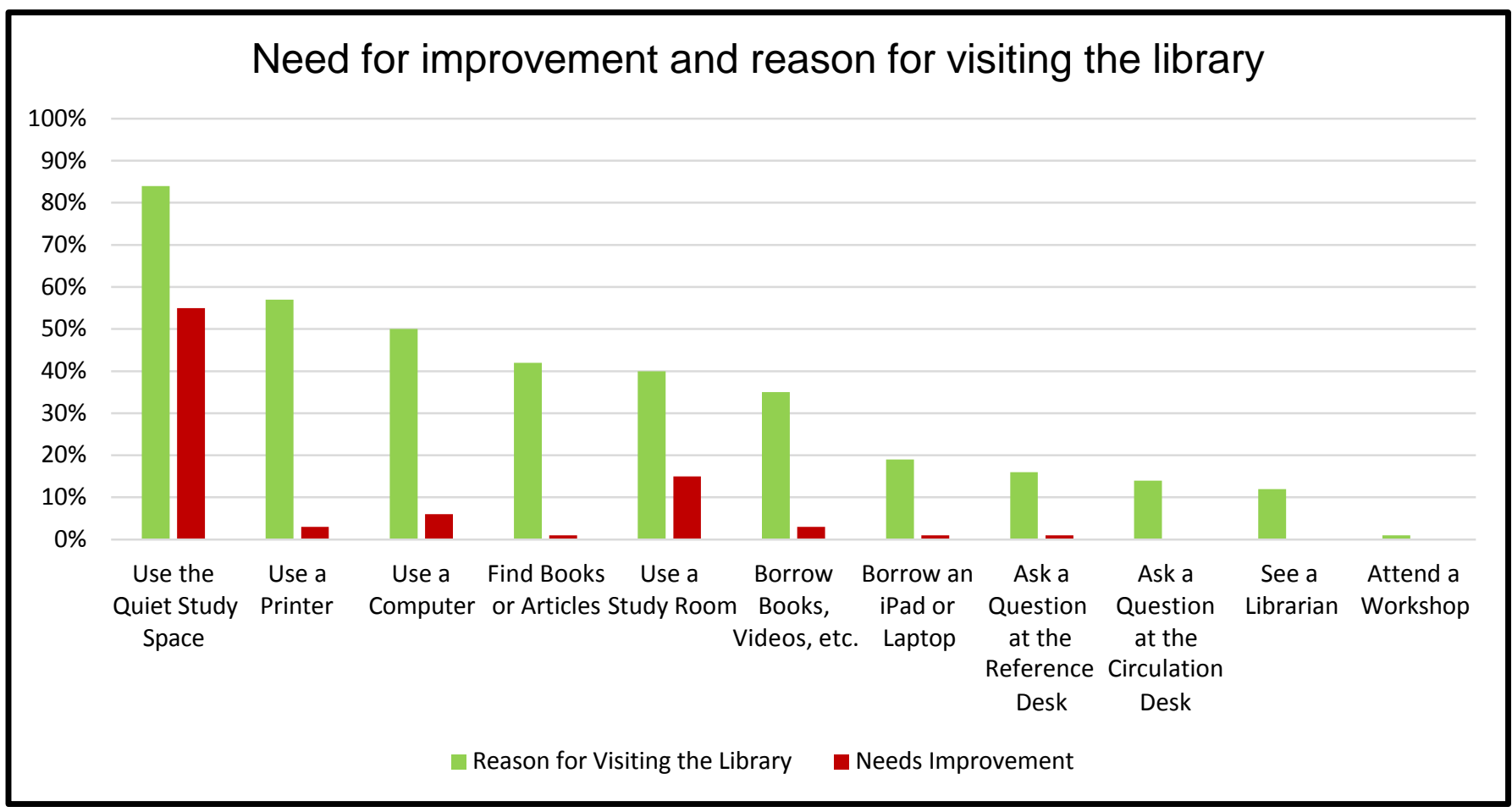

Figure 7. Percentage of respondents who indicated a specific reason for visiting the library along with the percentage of open comments suggesting improvements to an area or service that corresponded to that reason.

Another category that was important to students and received suggestions for improvement was computers. Respondents asked for more "express" computers that allow them to quickly check email or print their documents. 


\section{Satisfaction with Study Spaces}

After answering the open question about areas that need improvements, respondents were asked to agree or disagree with several statements regarding the adequacy of the library's study spaces and number of computers (Question 14). The responses, shown in Figure 8, indicate that the lighting is adequate, that seats are relatively comfortable, and that the library is sufficiently quiet. However, the students are not satisfied with the number of group study rooms, desktop computers, or the number of study spaces in general. This echoed the results from the previous question where most of the suggestions for improvement were about increasing the number of study spaces for either individual or group study.

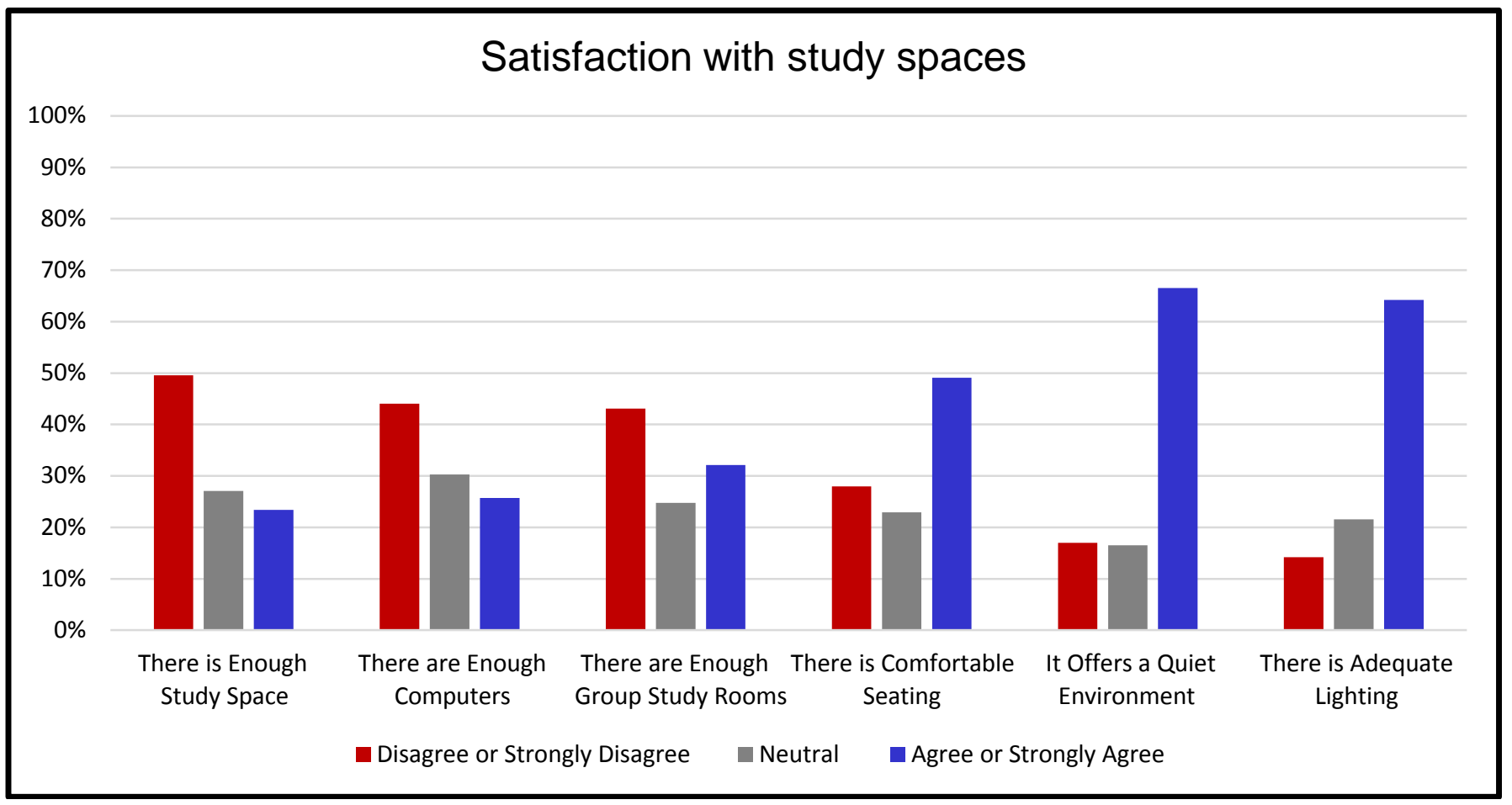

Figure 8. Respondents' satisfaction with study spaces.

The dissatisfaction with the number of desktop computers, was surprising. Although the survey did not explicitly ask about laptop ownership, according to an internal, unpublished university-wide survey from $2010,91 \%$ of Concordia students own a laptop. It is unlikely that laptop ownership has significantly declined since 2010 and Concordia Libraries also has a laptop lending service. While the service is well used, it is rare that all the laptops at the Vanier Library are in use at the same time. If respondents are expressing a desire for desktop computers, it is not because of the lack of availability of laptops, but rather a preference for desktop computers over laptops. A report by Dahlstrom, Walker and Dziuban found that the number one use for desktop computers is to access printing services and the second use is to act as a substitute for their personal laptops (26). 
Considering that a high percentage of respondents in our survey visit the library to print, the preference for desktop computers may be explained by the fact that printing is more convenient and straightforward using a desktop computer than using a laptop.

Respondents may also prefer desktop computers as there are almost never any issues with network access or power supply, and carrels with computers are much larger than the study tables.

Concordia Libraries has favoured the addition of laptops over desktop computers in the last few years reasoning that laptops are a device of choice for students allowing them to use different spaces in the library or even leave the library. When it comes to future computer acquisitions or modification to our laptop lending program, further investigation of students' rationale for preferring desktops over laptops would be wise. It would allow us to improve our service by either bringing the laptop's performance closer to students' expectations, or it will provide justification for increasing the number of desktop computers.

\section{Importance of Study Space Features}

Students were asked to rate the importance of different types of study spaces (Question 19). The results are presented in Figure 9.

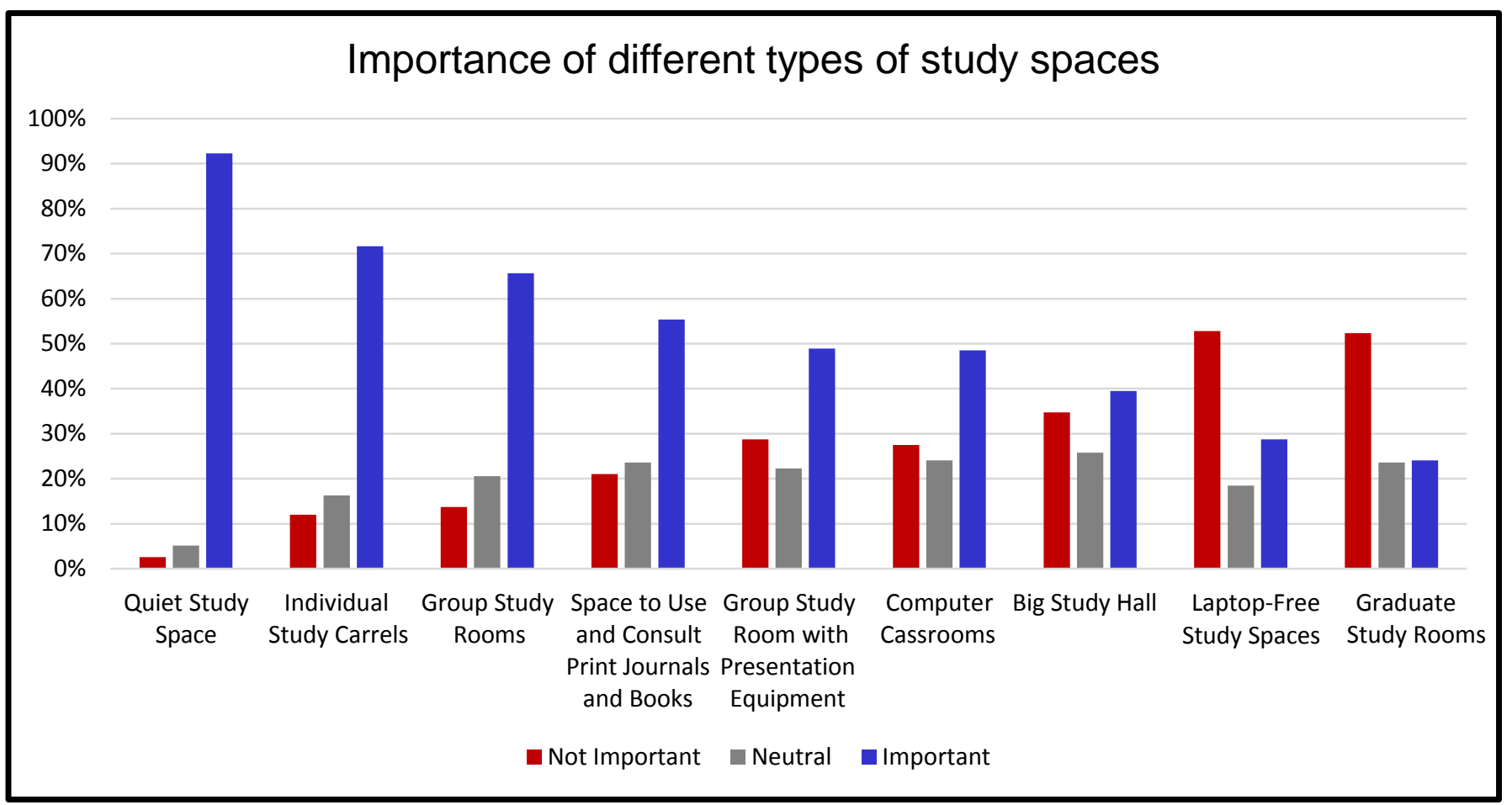

Figure 9. Importance of different types of study spaces.

\section{Furniture}

Quiet study space and individual study carrels were very important to most respondents. Vaska, Chan and Powelson's study found a similarly high preference 
(58\%) for study carrels. However, the high importance of study carrels in our study was somewhat surprising as the areas with study carrels are usually the last to be occupied. The focus group discussions revealed that having "individual" space is very important and since this survey question referred to "individual study carrels" it is quite possible that it has been rated as important by nearly all respondents because of the qualifier "individual," while "carrel" was of secondary importance or an unknown term.

From the focus groups and survey comments it is clear that opinions on study carrels are mixed. Some students mentioned that carrels make them feel claustrophobic; one focus group participant likened it to studying in a "beige box." Several participants in the focus groups spoke favourably of the carrels, saying they offered more privacy.

The focus groups' participants also spoke about individual tables for study. One participant expressed a preference for "a big desk" and another wanted "to be able to spread out." There were a few participants who went as far as quantifying the amount of space they need:

\section{We need at least three or four square metres}

One and a half square metres of table space is enough for me

There were several comments regarding study chairs, some of which were positive: "I like the white chairs" or "I love the wheeled chairs." One participant requested more chairs with wheels as they were lighter and "after a few hours of moving around instead of lifting the chair up, it's nice." There was another participant who did not like the chairs with wheels because they had arms which would bump into the desk and prevent them from sitting as close to the desk as they wished.

This diversity in response around the furniture just serves to reinforce the necessity of offering a wide selection of tables, carrels, and chairs for students to choose from when studying.

\section{Ambience and Light}

For all the improvement suggestions that were received for study spaces in Question 13 , there were recurring aspects or themes that pertained to atmosphere or ambience. They were frequently described in terms of emotion and comfort:

The environment is not very comfortable. The walls are bland and depressing, which makes one's mood become saddened. I would suggest upgrading the wall paint and tables for a more cheerful environment.

More plug outlets and nicer physical environment. I find the library very out of date.

Create a more open atmosphere for comfort for long hours of study. 
I would definitely change the lighting to something that is more bright; not the yellowish light. In my opinion it creates a strange atmosphere.

Similar themes emerged in the focus groups with one participant noting that the carpet made the library appear "worn and tired".

When developing the survey, questions surrounding ambience were hard to articulate. For example, Question 20 was an attempt to gain a sense of types of surroundings in which students like to study. Figure 10 shows the most preferred option was a study area with small clusters of tables with 53\% agreeing and only $23 \%$ disagreeing. The study space described as "large open study spaces with a lot of tables" was favoured by $43 \%$ of respondents with $31 \%$ disagreeing. While many respondents seem to like to study "surrounded by books" (44\%), there is a high percentage of those who do not care (30\%) or do not like to have books around (26\%). In hindsight, this question should have been better defined. For example, it is unclear if the question pertains to books in the study area (i.e., on shelves) or whether they study with lots of books around them at the table.

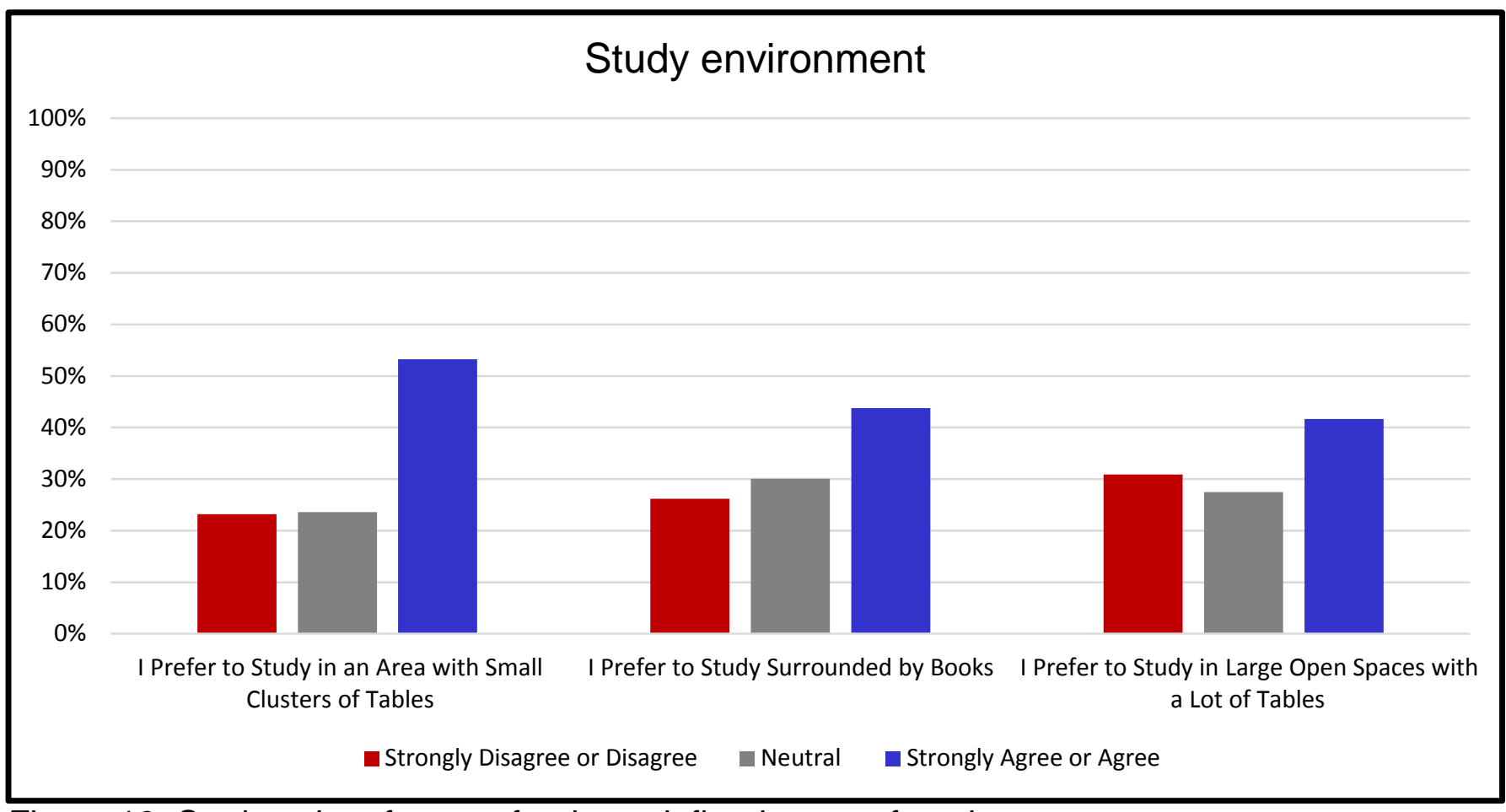

Figure 10. Students' preference for three defined types of study spaces.

In addition to expressing their preference for the three types of study spaces defined in the survey, respondents were invited to describe their ideal space. Their comments made clear the necessity for many diverse spaces for students to choose from: 
My ideal study space would have multiple different areas for different needs, sometimes I spend the whole day at the library! I love studying at the giant tables in front of the windows, but after a few hours I need a change of scenery

Quiet area, solitude, secluded, maybe a couple pillows (although unlikely). I like the private spaces that not many people know of.

A cubicle surrounded by other cubicles, with access to a power outlet and sufficient light at all times.

Light was often mentioned as an important feature. In Question 14, 64\% of respondents agreed that there was adequate lighting. However, the importance of lighting and requests for improved lighting were brought up frequently in the comments and in the focus groups. Many identified a seat by a window as being very valuable. This echoes the findings of Webb, Schaller and Hunley, who found that students frequently cited window views as rationale for their selection of one place over another.

Regarding the lighting, our students stated:

I love the second floor because I study among books but my window view is trees!

I need to be around windows in an open space or else I will feel claustrophobic.

I wish there was alternative lighting: the fluorescent (or whatever it is) lighting in the library makes it feel cold and institutional. A perfect library would have more welcoming lighting.

In the focus groups, light and specifically daylight was frequently mentioned. One of the students in the focus groups was very passionate about daylight and suggested installing 'light pipes' to bring daylight into study spaces that are not by the windows. Another student mentioned occasionally bringing in his own desk lamp to use in the library.

Good study ambience differs from person to person and can be hard to describe. However, the comments from respondents and focus group participants, while not providing concrete fixes for improving the atmosphere, emphasized good lighting, comfortable furniture and diversity in space as important features. Survey respondents and focus groups participants also made comments on the library décor describing it as dated and worn. One focus group participant even referred to it as "piecemeal décor", which highlights the importance of consistent, clean and well maintained furnishings.

Library ambience or atmosphere can be harder problem to tackle as it can require more structural changes to the building. Updating fixtures and furnishings that, while outdated, are still functional is hard to justify and may need to be done library-wide at 
the same time to avoid any jarring juxtaposition of outdated and modern design. Lighting can be hard to control as windows (or light pipes) cannot simply be added to the library building, and fluorescent light fixtures in the library are controlled by the university's facilities department.

\section{Wi-fi and Equipment}

Students were nearly unanimous in rating reliable Wi-Fi (97\%) and power outlets (92\%) as the most important features of their study space. Computers and laptops were also high on the list but tablets (e.g. iPads) were not (Figure 11). Initially, this was surprising because the library's tablet lending service is very popular. It was later discovered that its popularity was most likely due to the length of the loan period. The library loans tablets for three days while the laptops are loaned for six hours. When the three-day loan for laptops was introduced, students' preference was for laptops.

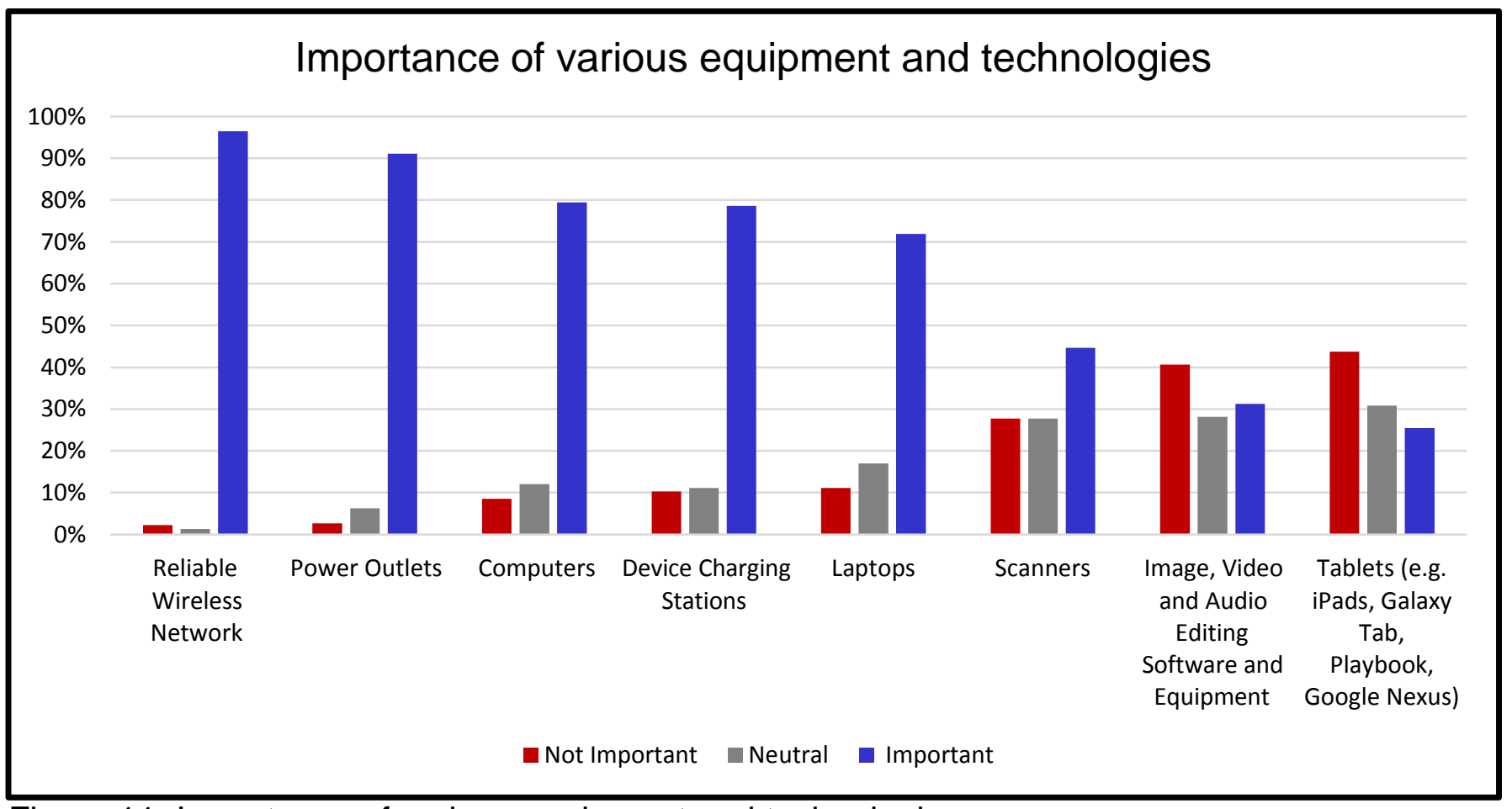

Figure 11. Importance of various equipment and technologies.

Related to power outlets, device-charging stations also came high on the list as $80 \%$ of respondents considered them important for their work. There are no charging stations in the library nor has there been much indication (either received through LibQual comments, suggestion box comments, or informal student comments at the service desks) that this is a highly desirable feature so this statistic was somewhat of a surprise. A better understanding of what this feedback really means would be necessary before taking any action in this direction. For example, are students stating that they would like the library to provide chargers that they can use in the available power outlets? Do they want a charging station where they could leave their devices? Or do they simply want more power outlets? 


\section{Other Desired Features}

The final question tried to ascertain whether there were any other types of spaces and services (e.g., lounge spaces, vending machines) that would increase student comfort while studying. The results are presented in Figure 12. A space where food is allowed was ranked important by $84 \%$ of respondents and $71 \%$ of respondents ranked "A coffee shop" as important.

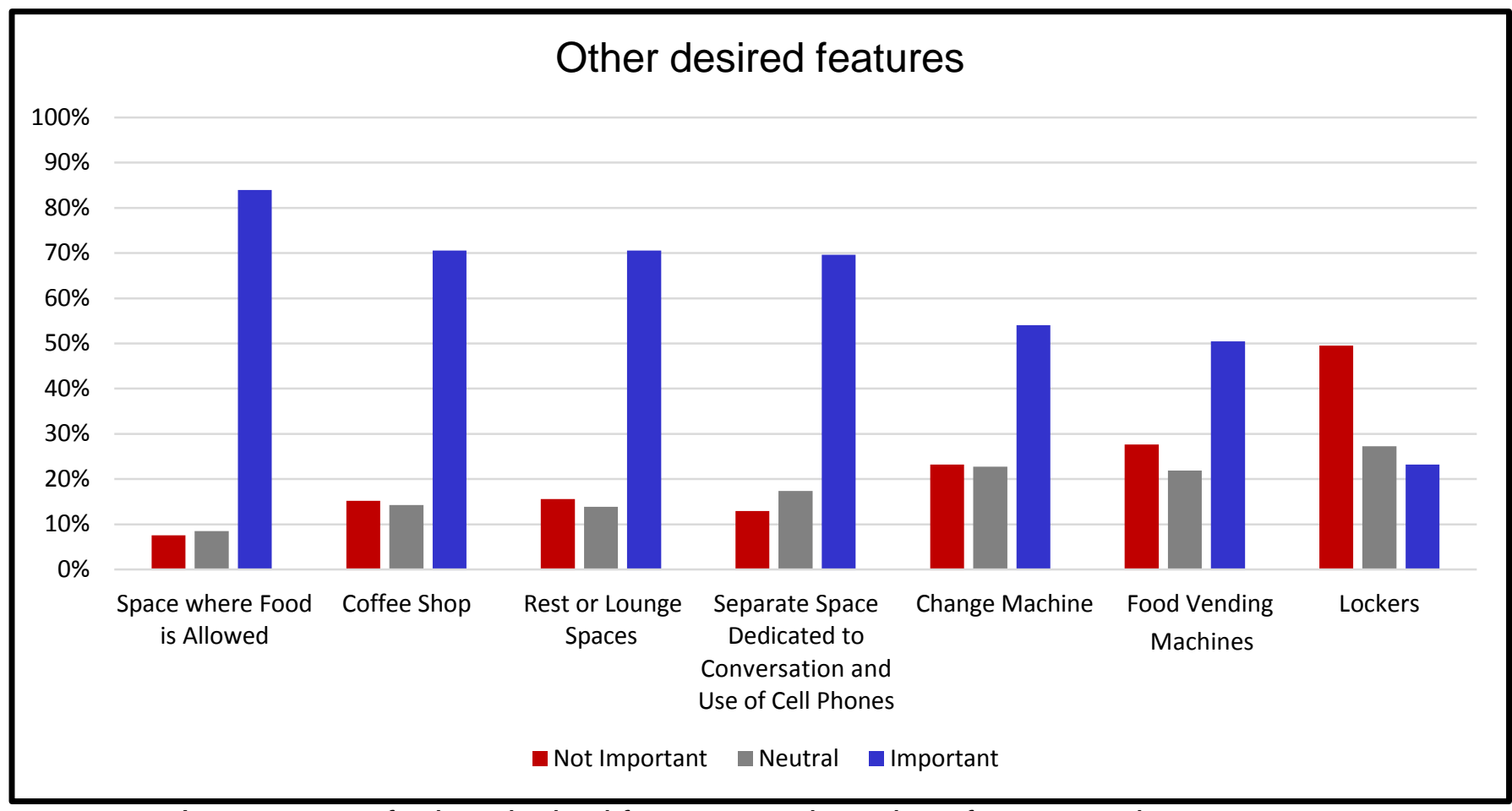

Figure 12. Importance of other desired features and services for respondents.

\section{Group Study}

From usage data and simple observation, group study rooms are known to be very popular. The survey had a few questions to help understand students' needs for this type of space. It was important to learn how often students work in groups, how big their groups are, what are the locations they like to meet and why, as well as what kind of equipment they need to support their group work. When considering renovations these questions address how many group study rooms are required, how big they should be, and what equipment, if any, to include.

Figure 13 shows the frequency with which students meet for group work with $37 \%$ of respondents meeting weekly (1-7 times per week), another 21\% meeting 1-2 times per month, and $42 \%$ meeting rarely or never. This is somewhat different from Brown-Sica's findings, which had a higher frequency of group work with $50 \%$ of participants meeting weekly, $36 \%$ monthly, and $14 \%$ meeting rarely (226). These differences may be due to areas of study or different pedagogical practices in place at each institution. 


\section{Frequency of group work}

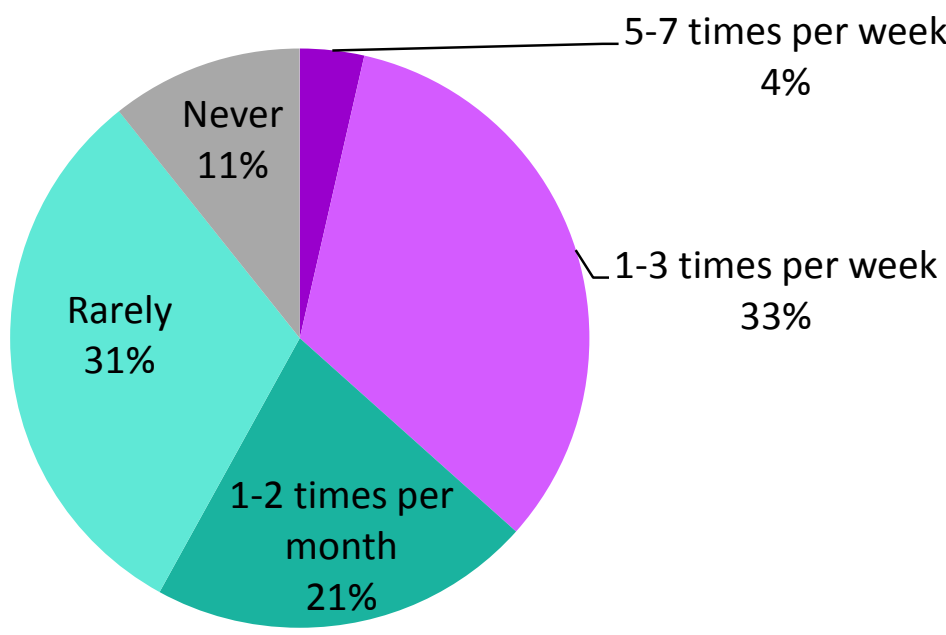

Figure 13. Frequency of group work.

The respondents' average group size is four or fewer people, with just $9.5 \%$ of respondents claiming average group size of more than four. The Vanier study rooms can accommodate up to six people. However, the results point to the need to have a small number of group study rooms that accommodate larger study groups. Over half (52\%) of the respondents who do group work meet in the library. Another $24 \%$ like to meet for group work in a coffee shop, while $15 \%$ meet in other spaces.

When asked why they prefer a certain location for group work, respondents stated that "space to spread out" was important (58\%). In apparent contradiction to the nature of group work, $47 \%$ said they like a place because it is quiet. The obvious explanation would be that they do not want other noise except their own. Some $19 \%$ of respondents, however, do like background noise. When the responses are analyzed by preferred location for group work (Figure 14), a correlation was discovered between respondents who choose the library study rooms and those with preference for quiet space and also the respondents who chose cafés and those who like background noise. Currently, there is no café in the library. If we would like to attract this group of students, who enjoy the café atmosphere for study, we would have to plan for one. 


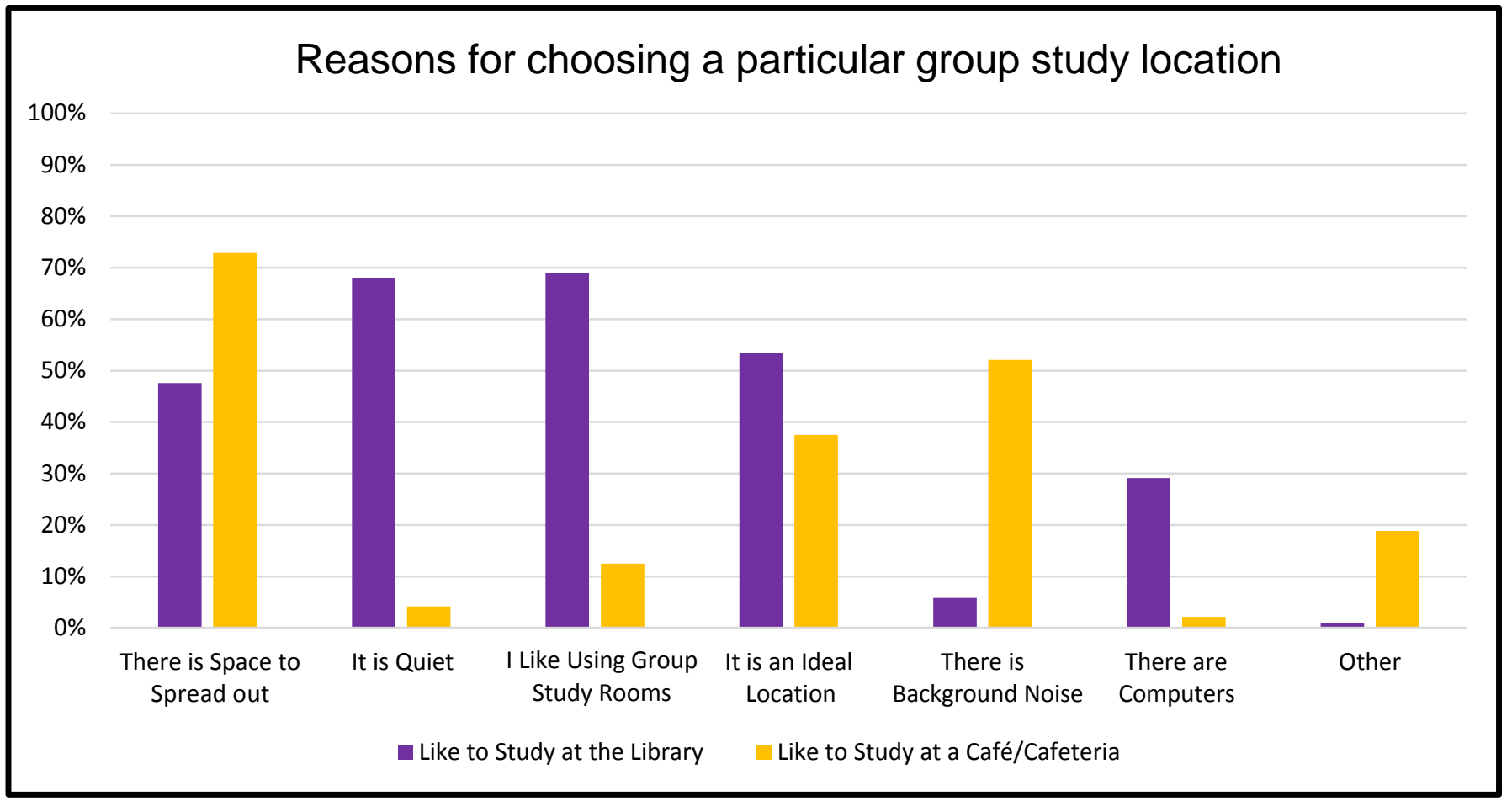

Figure 14. Reason for group work location preference.

In terms of room equipment (Figure 15), a whiteboard and computers were seen as necessary by the majority of our respondents, followed by the need for a projector. More complex technology such as smartboards and interactive screens are further down the list. In the focus groups, it was found that the ventilation in the group study rooms is poor and that students are uncomfortable if they close the door. This points to the importance of prioritizing basic conditions such as heating and ventilation, and equipment such as whiteboards and computers. Investing in high-end technology such as smartboards or interactive screens, would not necessarily result in student satisfaction with the group study rooms and the renovation process in general. 


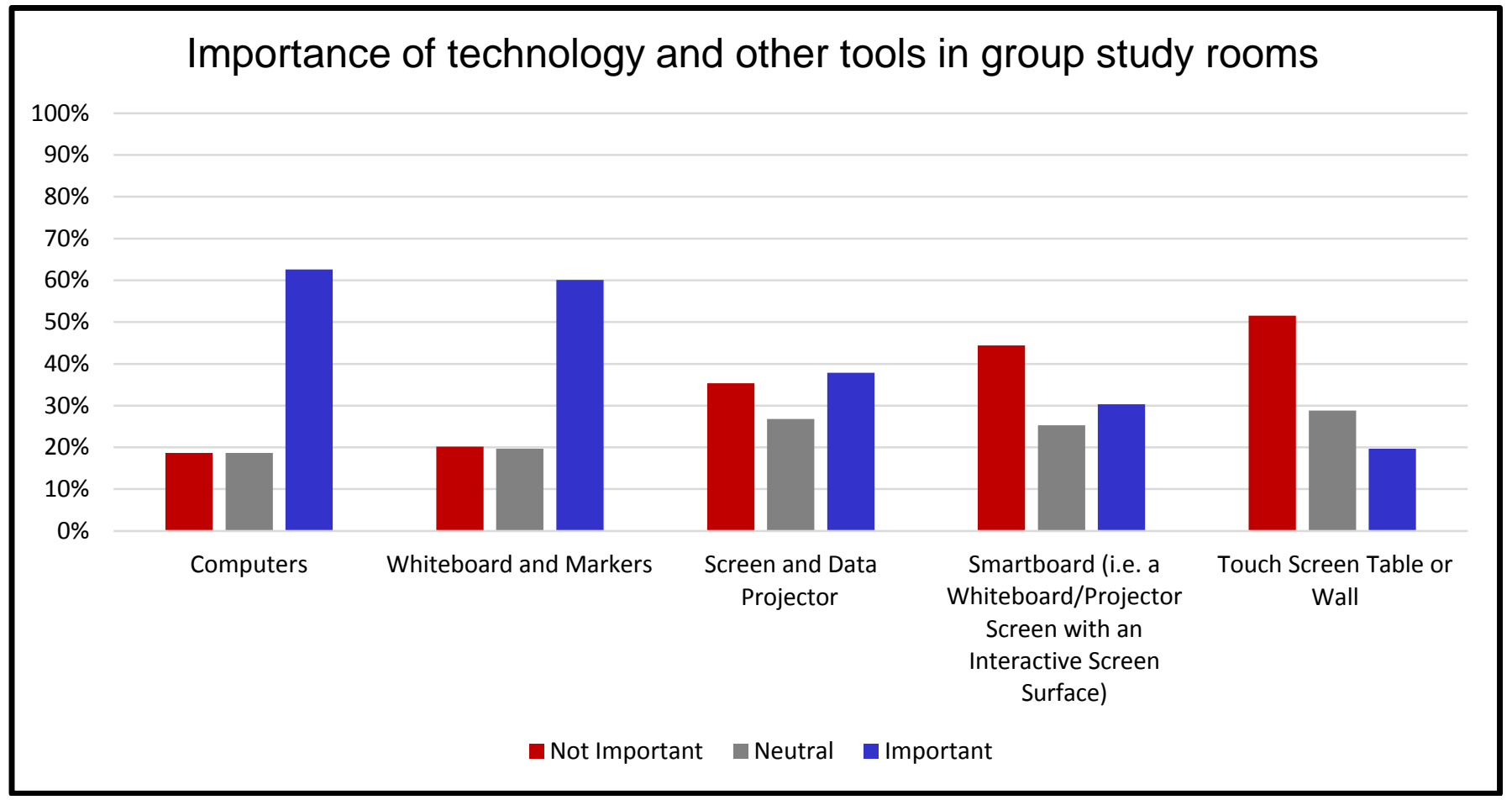

Figure 15. The importance of various technologies and tools in group study rooms.

\section{Assistance Services}

The layout and organization of the library service desks also play into space concerns and the layout of study space. The library currently has two service desks: a circulation desk and a reference desk but the activity at both desks is decreasing. There have been examples in the last few years of academic libraries merging service points and the authors wanted to see Loyola students' preference. When asked whether they would prefer to consult one general desk or one of several specialized desks, $67 \%$ of our respondents preferred to consult one general desk.

Students were also asked to rate different assistance services. Their answers are presented in Figure 16. Assistance with research and with the library technology was ranked as important by significant number of our respondents $(67 \%$ and $64 \%$, respectively). This is interesting when compared to what they say they do when they visit the library as only $16 \%$ claim to ask questions at the reference desk. A possible reason might be that many students are not aware that they can get assistance with their research in the library. 


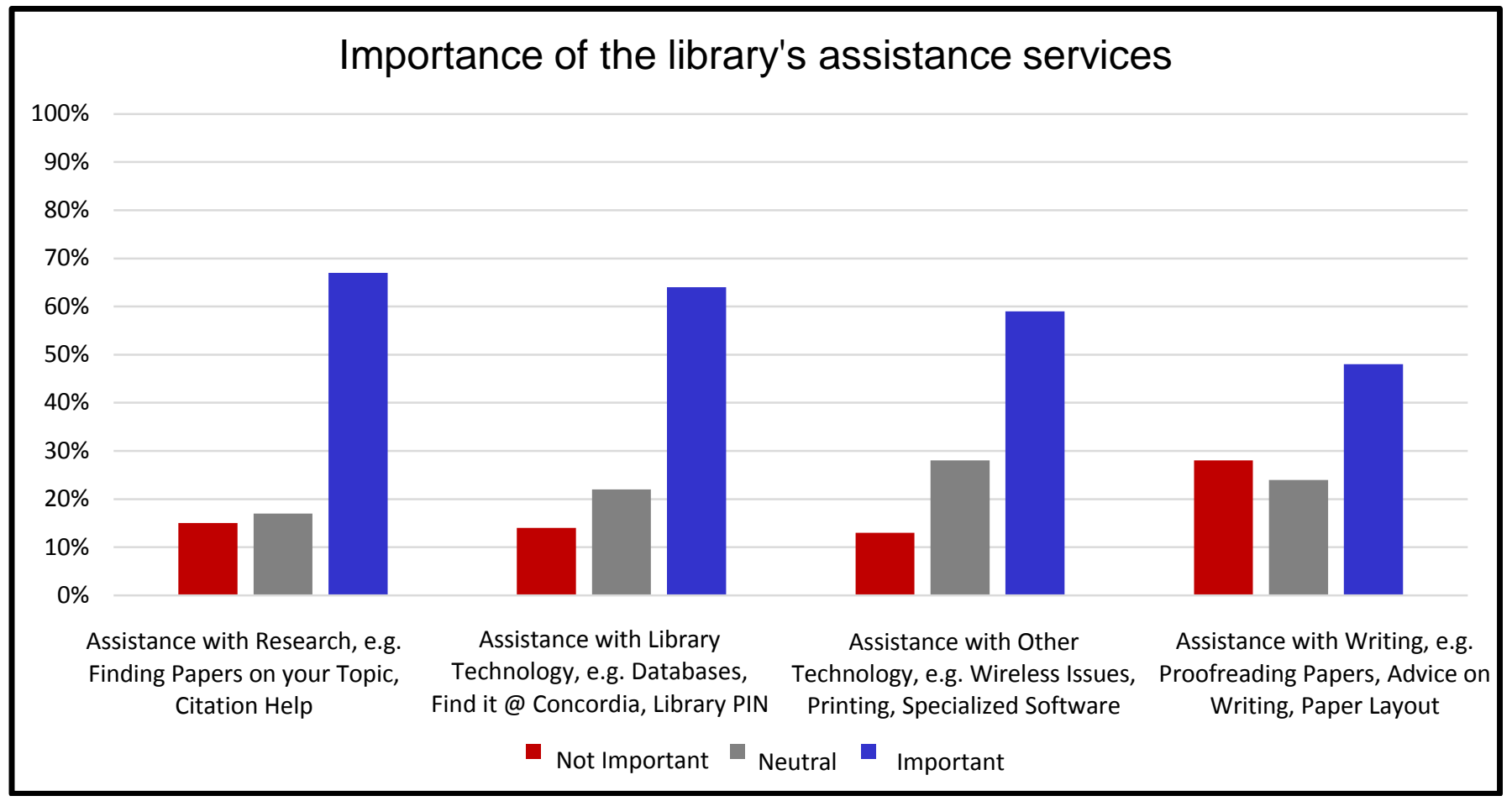

Figure 16. Importance of assistance services.

The Vanier Library's two service desks are located at the entrance of the library. It is possible that "Reference Desk" does not convey to students that research assistance might be offered there. Also, the majority of the study spaces are on the $2^{\text {nd }}$ and $3^{\text {rd }}$ floor of the library where no obvious assistance service exists. As the library has an online (chat) service, we put up posters on the $2^{\text {nd }}$ and $3^{\text {rd }}$ floors to advertise it. Statistics regularly collected for both in person and chat service show that questions asked via chat are mostly of research nature while the reference desk answers a lot of directional questions and provides assistance with equipment and software.

Services such as help with printers and Wi-Fi are desired by $59 \%$ of respondents. In Brown-Sica's study, 38\% of respondents wanted assistance with computer applications and $25 \%$ wanted a representative from the main IT department (225). Our question explicitly stated assistance with printing and the survey coincided with the implementation of a new printing service that had required a lot of assistance. Although services such as printing and Wi-Fi are managed by other departments, the library already provides basic help at the reference desk. The services not provided such as assistance with writing and proofreading papers was also deemed important by a significant number of respondents (48\%), although this number is slightly less than the 59\% found in the Brown-Sica study (225).

\section{Summary and Improvements Made}

The purpose and place of libraries on university campuses is changing. Only $35 \%$ of survey respondents come to the library to borrow material while $84 \%$ visit the library to 
use the quiet study space. The majority of respondents use the library several times per week (77.6\%). A good number of them (37\%) also need to meet in teams on a weekly basis as part of their school work.

The results from this survey show that the respondents who use the service points most frequently are not necessarily the students who use the study spaces the most. Loyola campus science respondents, for example, use the space more frequently than any other discipline on campus while Applied Human Sciences respondents are much more inclined to use staff mediated services and group study rooms. This study reveals how the library staff's perception of student needs, based on their experience at service desks, might miss a whole group of students, such as science students, for example, who rarely use staff mediated services.

In addition to indicating the desire for more study places, results of the survey indicate that students see ambience as very important for their study. We were impressed with the number of students who pointed, without prompting, to the overall look and feel of the library as a very important factor for creating a good study atmosphere. Not surprisingly, light (and specifically day light), as well as the comfort of the furniture are high on the list. Although we received some harsh comments, most students seem satisfied with the quietness of the library and lighting.

\section{Study Spaces}

With upcoming renovations it was necessary to know how to best rearrange the study spaces to minimize their impact on students. As the results of the study showed that respondents heavily use and desire more quiet study spaces, we changed the proportion of the library's existing study zones so that approximately two-thirds of the study spots are in a quiet zone.

A larger increase to the number of individual study spaces would require the purchase of new furniture. Almost all study tables in the library seat four students, however the size of the tables does not allow for comfortable private study for four students. Fortunately, we received some funding from the Concordia Student Union that allowed us to replace the tables in one of the library's quiet study areas with new ones more supportive of private study.

\section{Group Study Rooms}

We were able to lobby for the addition of two new group study rooms to be included in the renovation plans, along with upgrading two existing rooms. Knowing that technological gadgets, such as "smart touch tables," are not highly rated by our students, the library was able to focus technological improvements to the basics such as replacing the old wall-mounted blackboards with mobile boards. These proved to be very popular and we would often find them arranged in different ways to suit students' group work. For example, chemistry students will put together three or four boards to create a big panel for writing long formulas. Screens and data projectors were also 
highly ranked so the library invested in the collaboration equipment that allowed students to display content from several laptops on a plasma screen.

These rooms are very popular and well used. When planning future renovations, we would like to convert some of the existing groups study areas to actual group study rooms. This would allow privacy to a group as well as reduce general noise level in the study area.

\section{Wi-Fi and Computers}

After analyzing the results of the survey, Concordia University's IT department was engaged to evaluate spaces that did not have optimal Wi-Fi coverage. New access points were installed where it was deemed necessary. Twelve more computers workstations were also installed and there will be more power outlets installed in the near future so there is, at least, one power outlet per study seat.

The library needs to learn more about the students' use of desktop computers, laptops, and printers. This study attempted only to understand how important these features are in relation to how much space should be devoted to them. More information is needed in order to understand the specific needs students have of these services and consequently how to make improvements. Answering such questions may influence the space allocated to desktop computers, for example.

\section{Food Areas}

A space where food is allowed was ranked important by $84 \%$ of respondents and $71 \%$ of respondents ranked "A coffee shop" as important. We have created an area where food is permitted on the $2^{\text {nd }}$ and $3^{\text {rd }}$ floor of the library. While many students use these "food zones", many continue to eat in study areas where food is not allowed. Eventually we might create some study zones where food is allowed but it will be hard to find a balance between all the different preferences. For example, 84\% of respondents want space where food is allowed, yet $84 \%$ of them visit the library for the quiet study areas where, one would assume, eating should not be allowed as it creates disturbance.

Shortly after the study was conducted a student-managed coffee shop opened in the building where the library is and the library director decided that adding one in the library would not make much of an impact.

\section{Conclusion}

We were able to use the results of our study to make improvements to the library's quiet study space, group study rooms, Wi-Fi network, and computers, as well as create areas where food is allowed. The changes we made are still a long way from satisfying all of the desires of the student community expressed in the survey; however, having the survey and focus group data helped the library to prioritize its efforts. The results of our survey also indicate some differences in student use of study spaces based on 
academic program that may point to a need for a more targeted study of different student groups.

\section{Acknowledgements}

The authors would like to thank our Applied Human Science collaborators, Dr. Rosemary Reilly, Dena Duijkers, Julien Castonguay and Pascale Geoffroy as well as our MLIS student assistant, Emily Kingsland. Additionally, we would like to thank the librarians and staff at the Vanier Library who participated in development of survey question and in analyzing the results of the focus groups.

\section{Works Cited}

Association of Research Libraries. LibQual+ 2013 Survey. Concordia University Libraries. Washington, DC: ARL, 2013. Web. 20 Mar. 2013.

Bailin, Kylie. "Changes in Academic Library Space: A Case Study at the University of New South Wales." Australian Academic \& Research Libraries 42.4 (2011):342359. Taylor \& Francis Online. Web. 29 May 2012.

Brown-Sica, Margaret S. "Library Spaces for Urban, Diverse Commuter Students: A Participatory Action Research Project." College \& Research Libraries 73.3 (2012): 217-31. Web. 29 May 2012.

Bryant, Joanna, Graham Matthews, and Graham Walton. "Academic Libraries and Social and Learning Space: A Case Study of Loughborough University Library, UK." Journal of Librarianship and Information Science 41.1 (2009): 7-18. SAGE Journals. Web. 11 Apr. 2014.

Collins, Ellen and Graham Stone. "Understanding Patterns of Library Use Among Undergraduate Students from Different Disciplines." Evidence Based Library and Information Practice 9.3 (2014): 51-67. Web. 26 Feb. 2015.

Creaser, Claire. "User Surveys in Academic Libraries." New Review of Academic Librarianship 12.1 (2006): 1-15. Taylor \& Francis Online. Web. 26 Feb. 2015.

Dahlstrom, Eden, J. D. Walker, and Charles Dziuban. ECAR Study of Undergraduate Students and Information Technology, 2013. Louisville, CO: EDUCAUSE. PDF File.

De Rosa, Cathy et al. Perceptions of Libraries, 2010: Context and Community. Dublin, OH: OCLC, 2010. Web. 5 May 2014.

Centre for Analysis and Research, 2013. Web. 2 May 2014. 
OCLC. College Students' Perceptions of Libraries and Information Resources: A Report to the OCLC Membership. Dublin, OH: OCLC, 2005. Web. 2 May 2014.

Magrill, Rose Mary, and Gloriana St. Clair. "Undergraduate Term Paper Citation Patterns by Discipline and Level of Course." Collection Management 12.3/4 (1990): 25-56. Print.

Vaska, Marcus, Rachel Chan, and Susan Powelson. "Results of a User Survey to Determine Needs for a Health Sciences Library Renovation." New Review of Academic Librarianship 15.2 (2009): 219-34. Taylor \& Francis Online. Web. 11 Apr. 2014.

Walton, Graham. "Learners' Demands and Expectations for Space in a University Library: Outcomes from a Survey at Loughborough University." New Review of Academic Librarianship 12.2 (2006): 133-49. Taylor \& Francis Online. Web. 11 Apr. 2014.

Webb, Kathleen M., Molly A. Schaller, and Sawyer A. Hunley. "Measuring Library Space Use and Preferences: Charting a Path Toward Increased Engagement." Libraries and the Academy 8.4 (2008): 407-22. Project MUSE. Web. 27 Feb. 2013. 


\section{Appendix 1. Vanier Library Space Survey}

Concordia Libraries is in the beginning stages of a major space re-organization project. The overall goal is to improve student spaces and access to library materials. At the moment we are seeking student opinion on the study space at the VANIER LIBRARY on the Loyola Campus.

This survey is anonymous. Your participation is voluntary. You may choose not to take the survey or to stop responding at any time. Your completion of the survey serves as your voluntary agreement to participate in this project.

It will take approximately 10 minutes to complete.

\section{Please indicate your age range.}

Under 18

( $\quad 18-22$

○ 23-30

o $\quad 31-45$

( $46-65$

O Over 65

Prefer not to answer

\section{I am}
. Male
- Female
C Prefer not to answer

\section{How close do you live to the Loyola campus?}

I live on campus

- I live in the neighbourhood

I live downtown

- I live elsewhere

\section{I am}

- An undergraduate student

- An honours undergraduate student

- A graduate student

O I am not a student 


\section{Appendix 1. Vanier Library Space Survey}

\section{I am}

a part time student

a full time student (taking 4 or more courses)

other, please specify:

\section{I am}

a Québec student

an out of province student

an international student

\section{Is this your first semester at Concordia?}
Yes
No

\section{Where do you have the majority of your classes?}

Loyola Campus

- Sir George William Campus

\section{What is your program of study?}
Communications
Exercise Science
Independent Student
Journalism
Chem \& Biochem
Other
Applied Human Sciences
Biology
Psychology
Physics

If other, please specify:

\section{How often do you use the VANIER library?}
5-7 times per week
1-3 times per week
1-2 times per month
Rarely
Never, I prefer to use the library website
Never, I use another library
Never, I don't use libraries 


\section{Appendix 1. Vanier Library Space Survey}

\section{What other library do you use? Why?}

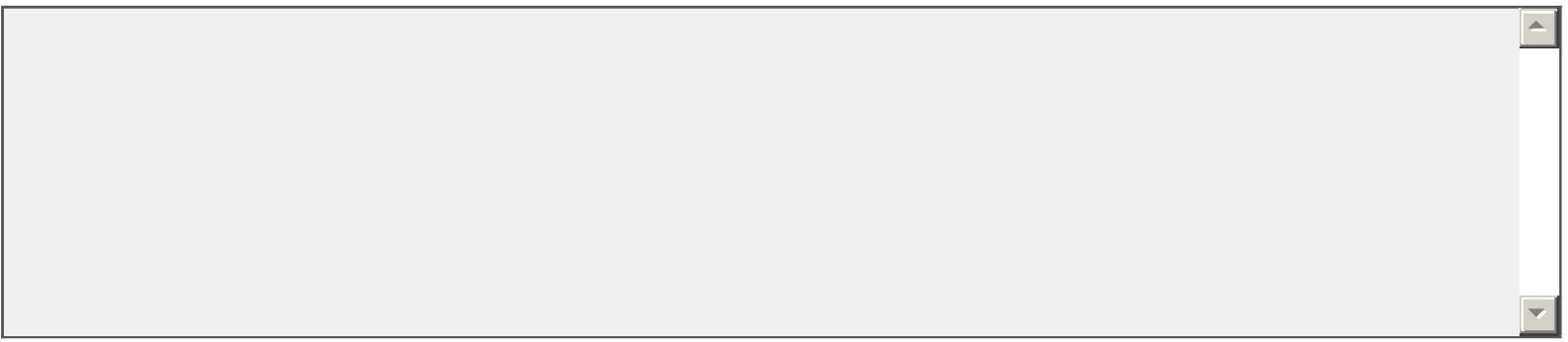

\section{What do you do when you visit the library? Please check all that apply.}

$\square$ use the quiet study space

$\square$ ask a question at the Circulation Desk

ए use a study room

$\lceil$ borrow an iPad or laptop

$\square$ meet up with friends

C consult an item in Special Collections

$\Gamma$ find books or articles

- use a computer

[ borrow books, videos, etc.

ᄃ use a printer

— see a librarian

- attend a workshop

ए ask a question at the Reference Desk

$\square$ other

If other, please specify:

13. If there was one thing you could improve about the Vanier Library what would it be?

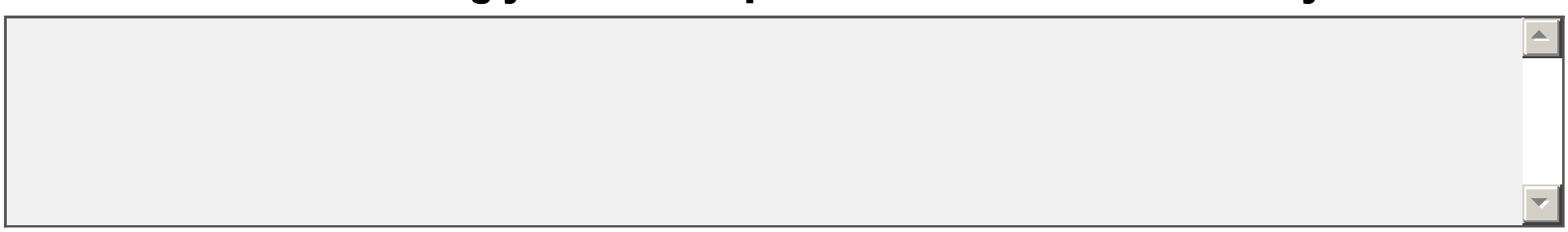

14. Consider the following statements with respect to the Vanier Library. Please indicate whether you agree or disagree.

There is enough study space

$$
\begin{gathered}
1 \text { - Strongly } \\
\text { Disagree }
\end{gathered}
$$

There are enough computers

There are enough group study rooms

There is comfortable seating

It offers a quiet environment

There is adequate lighting

$\begin{array}{ll}0 & 0 \\ 0 & 0 \\ 0 & 0 \\ 0 & 0 \\ 0 & 0 \\ 0 & 0\end{array}$

3

0

0

c

c

c

o
5 - Strongly Agree

O

0

o

0

o 


\section{Appendix 1. Vanier Library Space Survey}

15. Have you ever consulted materials in the Libraries' Special Collections?

Yes

No

I don't know

16. We will be conducting a focus group that is specific to the space needs of the Libraries' Special Collections. If you are interested in participating in the focus group, please leave your e-mail address below.

This email address will only be used for the purpose of contacting you regarding the Special Collections focus group. If you would prefer to contact us, you may do so at libVanierReference@concordia.ca

I am not interested

I am interested, here is my email address:

17. When seeking library staff for help, would you prefer to:

C Consult one general desk

Consult one of several specialized desks

18. Please indicate how important the following services are in your academic work.

$$
\begin{aligned}
& 1 \text { - Not } \\
& \text { Important }
\end{aligned}
$$

Assistance with research, e.g. finding papers on your topic, citation help.

Assistance with library technology, e.g. databases, find it @ Concordia, Library PIN Assistance with other technology, e.g wireless issues, printing, specialized software Assistance with writing, e.g. proofreading papers, advice on writing, paper layout

Please tell us if there are any other services you consider important: 


\section{Appendix 1. Vanier Library Space Survey}

19. Please indicate how important the following study spaces are in your academic work.

Quiet study space

$$
\begin{gathered}
1 \text { - Not } \\
\text { Important }
\end{gathered}
$$

Individual study carrels

Graduate study rooms

Big study hall

Laptop-free study spaces

Group study rooms

Group study room with presentation equipment

\section{Computer classrooms}

Space to use and consult print journals and books

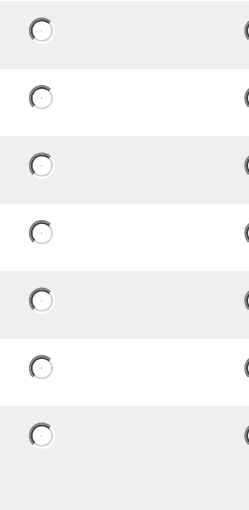

$0 \quad 0$

O

0

2

3

0

○

o

0

0

0

0
5 - Extremely Important

Please tell us if there is any other type of study space you consider important:

\section{Consider the following statements. Please indicate whether you agree or disagree.}

$\begin{aligned} & 1 \text { - Strongly } \\ & \text { Disagree }\end{aligned}$
$\begin{aligned} & \text { I prefer to study in large open spaces with a } \\ & \text { lot of tables }\end{aligned}$

If you like, please describe your ideal study space below: 


\section{Appendix 1. Vanier Library Space Survey}

\section{Please indicate how important the following equipment is in your academic work.}

Reliable wireless network

$$
\begin{gathered}
1 \text { - Not } \\
\text { Important }
\end{gathered}
$$

Scanners

Image, video and audio editing software and equipment

Computers

Laptops

Tablets (e.g. iPads, Galaxy Tab, Playbook, Google Nexus)

Power outlets

Device charging stations

Please tell us if there is any other equipment you consider important:

\section{Please indicate how important the following "extras" are to your comfort while} studying.

$$
\begin{gathered}
1 \text { - Not } \\
\text { Important }
\end{gathered}
$$

Separate space dedicated to conversation and use of cell phones

Rest or lounge spaces

Coffee shop

Food vending machines

Space where food is allowed

Lockers

Change machine

2

○

0

$\circ$

\section{6}

0

6

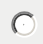

○
5 - Extremely Important

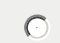

○

6

$\circ$

6

$\circ$

6

6

Please tell us if there are any other "extras" you consider important:

\section{How often do you meet to work in a group?}

- 5-7 times per week

- 1-3 times per week

- 1-2 time(s) per month

o Rarely

O Never 


\section{Appendix 1. Vanier Library Space Survey}

\section{On average, how big are your study groups?}

( $\quad$ 1-4 people

More than 4 people

\section{Where do you like to meet for group work?}
- The cafeteria
The Hive
O The library
- A classroom
- A coffee shop
Other (please specify):

\section{In the previous question you answered "[Q25]"}

\section{Can you tell us why you like to meet there for group work? Please check all that apply.}

$\square$ It is quiet

$\square$ There is background noise

$\Gamma$ There is space to spread out

$\square$ There are computers

$\square$ I like using group study rooms

$\square$ It is an ideal location

$\Gamma$ Other

If other, please specify:

\section{How important is it for a group study room to have the following technology?}

Screen and data projector

Touch screen table or wall

Whiteboard and markers

Computers

Smartboard (i.e. a whiteboard/projector screen with an interactive screen surface)

$$
\begin{aligned}
& 1 \text { - Not } \\
& \text { Important }
\end{aligned}
$$

$\begin{array}{ll}0 & 0 \\ 0 & 0 \\ 0 & 0 \\ 0 & 0 \\ 0 & 0\end{array}$

Please tell us if there is any other technology you consider important:
5 - Extremely Important

0

○

6

6

6 


\section{Appendix 1. Vanier Library Space Survey}

28. We plan to follow up this survey by conducting focus groups. These focus groups will take place over the lunch hour and a light meal will be provided. If you are interested in being contacted to participate in a focus group about the Vanier Library, please leave your email address below.

This email address will only be used for the purpose of contacting you regarding this library focus group. If you would prefer to contact us, you may do so at libVanierReference@concordia.ca

○ I am not interested

I am interested, here is my email address: 


\section{Appendix 2. Schedule of questions for Vanier Library Focus Groups}

\section{Opening}

1. What are your study habits?

Introductory:

2. When do you come to study in the library?

3. Why do you study in the library? (probe)

\section{Transition}

4. Think back to when you physically entered in the library. How does the library make you feel?

\section{Key questions}

5. What kind of study spaces do you need in the library?

6. How much physical space do you need? (probe)

7. What kind of furniture fosters your study session? (probe)

8. What kind of lighting do you prefer when studying? (probe)

9. How does food factor into your studying? (probe)

10. What technology is helpful to you when you study? (probe)

11. What do you think of the study rooms?

12. What improvements could be done to the study rooms to improve your experience with them? (probe)

\section{Ending questions}

13. Envisioning your ideal study space, what would it be?

14. How would you like to feel while entering into the library?

15. After all you have heard during this focus group, what kind of advice would you give the library to redesign study spaces? 